\title{
Design and Analysis Tool for External-Compression Supersonic Inlets
}

John W. Slater

Glenn Research Center, Cleveland, Ohio 


\section{NASA STI Program . . . in Profile}

Since its founding, NASA has been dedicated to the advancement of aeronautics and space science. The NASA Scientific and Technical Information (STI) program plays a key part in helping NASA maintain this important role.

The NASA STI Program operates under the auspices of the Agency Chief Information Officer. It collects, organizes, provides for archiving, and disseminates NASA's STI. The NASA STI program provides access to the NASA Aeronautics and Space Database and its public interface, the NASA Technical Reports Server, thus providing one of the largest collections of aeronautical and space science STI in the world. Results are published in both non-NASA channels and by NASA in the NASA STI Report Series, which includes the following report types:

- TECHNICAL PUBLICATION. Reports of completed research or a major significant phase of research that present the results of NASA programs and include extensive data or theoretical analysis. Includes compilations of significant scientific and technical data and information deemed to be of continuing reference value. NASA counterpart of peer-reviewed formal professional papers but has less stringent limitations on manuscript length and extent of graphic presentations.

- TECHNICAL MEMORANDUM. Scientific and technical findings that are preliminary or of specialized interest, e.g., quick release reports, working papers, and bibliographies that contain minimal annotation. Does not contain extensive analysis.

- CONTRACTOR REPORT. Scientific and technical findings by NASA-sponsored contractors and grantees.
- CONFERENCE PUBLICATION. Collected papers from scientific and technical conferences, symposia, seminars, or other meetings sponsored or cosponsored by NASA.

- SPECIAL PUBLICATION. Scientific, technical, or historical information from NASA programs, projects, and missions, often concerned with subjects having substantial public interest.

- TECHNICAL TRANSLATION. Englishlanguage translations of foreign scientific and technical material pertinent to NASA's mission.

Specialized services also include creating custom thesauri, building customized databases, organizing and publishing research results.

For more information about the NASA STI program, see the following:

- Access the NASA STI program home page at http://www.sti.nasa.gov

- E-mail your question to help@sti.nasa.gov

- Fax your question to the NASA STI Information Desk at 443-757-5803

- Phone the NASA STI Information Desk at 443-757-5802

- Write to: STI Information Desk NASA Center for AeroSpace Information 7115 Standard Drive Hanover, MD 21076-1320 


\section{Design and Analysis Tool for External-Compression Supersonic Inlets}

John W. Slater

Glenn Research Center, Cleveland, Ohio

Prepared for the

50th Aerospace Sciences Meeting

sponsored by the American Institute of Aeronautics and Astronautics

Nashville, Tennessee, January 9-12, 2012

National Aeronautics and

Space Administration

Glenn Research Center

Cleveland, Ohio 44135 


\section{Acknowledgments}

The author would like to acknowledge the support of the Supersonics Project under the NASA Fundamental Aeronautics Program.

Trade names and trademarks are used in this report for identification only. Their usage does not constitute an official endorsement, either expressed or implied, by the National Aeronautics and Space Administration.

This work was sponsored by the Fundamental Aeronautics Program at the NASA Glenn Research Center.

Level of Review: This material has been technically reviewed by technical management.

Available from

NASA Center for Aerospace Information 7115 Standard Drive

Hanover, MD 21076-1320
National Technical Information Service 5301 Shawnee Road Alexandria, VA 22312 


\title{
Design and Analysis Tool for External-Compression Supersonic Inlets
}

\author{
John W. Slater \\ National Aeronautics and Space Administration \\ Glenn Research Center \\ Cleveland, Ohio 44135
}

\begin{abstract}
A computational tool named SUPIN has been developed to design and analyze external-compression supersonic inlets for aircraft at cruise speeds from Mach 1.6 to 2.0. The inlet types available include the axisymmetric outward-turning, two-dimensional single-duct, two-dimensional bifurcated-duct, and streamline-traced Busemann inlets. The aerodynamic performance is characterized by the flow rates, total pressure recovery, and drag. The inlet flowfield is divided into parts to provide a framework for the geometry and aerodynamic modeling and the parts are defined in terms of geometric factors. The lowfidelity aerodynamic analysis and design methods are based on analytic, empirical, and numerical methods which provide for quick analysis. SUPIN provides inlet geometry in the form of coordinates and surface grids useable by grid generation methods for higher-fidelity computational fluid dynamics (CFD) analysis. SUPIN is demonstrated through a series of design studies and CFD analyses were performed to verify some of the analysis results.
\end{abstract}

\section{Introduction}

The pursuit of sustainable commercial supersonic flight has lead to recent conceptual studies for aircraft with cruise speeds between Mach 1.6 and 2.0 with the goal of supersonic flight over land (Refs. 1 and 2). Among the challenges are reducing sonic boom signatures and developing an efficient propulsion system. The design of the inlet for the propulsion system is included among the challenges (Ref. 3).

The role of the inlet is to capture a required amount of airflow and deliver it to the engine at conditions suitable for the stable and efficient operation of the propulsion system. For cruise speeds below Mach 2.0, an external-compression supersonic inlet is considered a good choice due to potentially high total pressure recovery with stable operating characteristics (Refs. 4 to 6). An external-compression supersonic inlet compresses the supersonic flow along the external surfaces of the inlet using shock and Mach waves while decelerating the flow to lower supersonic speeds. A strong shock situated at the entrance of the inlet decelerates the flow from supersonic to subsonic speeds. The subsonic flow is then ducted to a gas turbine engine while being decelerated and compressed through an increase in the crosssectional area of the subsonic diffuser.

The design and analysis of external-compression supersonic inlets has been a topic of research and development for over 60 years. Ferri and Nucci provided some of the earliest design guidelines for the angles and placements of the centerbody cone and cowl for an axisymmetric inlet (Ref. 7). A conical centerbody turns the flow outward from an axis-of-symmetry and establishes conical shock and Mach waves, which compress and decelerate the supersonic flow. The use of a conical compression was facilitated in part by the ability to analytically compute the conical shock properties using equations such as those of Taylor and Maccoll for supersonic flow past a cone (Ref. 8). Oswatitsch also studied axisymmetric external-compression inlets and considered multiple stages for the centerbody with stage angles selected to maximize the total pressure recovery of the external supersonic diffuser (Ref. 9). The axisymmetric, external-compression inlet was used for a variety of ramjet missiles and supersonic military aircraft. Its use on the Mach 2.0 B-58 Hustler bomber provides an important example (Ref. 10). 
Axisymmetric inlets were used on the A-12/YF-12/SR-71 series of Mach 3.0+ aircraft for external compression; however, that inlet also incorporated internal supersonic compression to retain efficiency above Mach 2.0 (Ref. 11). Axisymmetric inlets continue to be studied for use for future supersonic transports. The conceptual study by Lockheed Martin suggested axisymmetric inlets for its supersonic transport (Ref. 2). The Gulfstream Aerospace Corporation has studied supersonic transports utilizing axisymmetric inlets and its low-boom, axisymmetric inlet has been analyzed and tested at the NASA Glenn Research Center (Refs. 3 and 12).

Two-dimensional supersonic compression is another option for the external supersonic diffuser and involves compression through oblique shock and Mach waves. The flow properties through oblique shock and Mach waves can be determined analytically using compressible flow relations such as those in NACA Report 1135 or compressible flow textbooks (Refs. 13 and 14). Two-dimensional, externalcompression inlets have been studied and developed for a variety of aircraft. The US Air Force F-15 Eagle aircraft has side-mounted two-dimensional inlets that each fed an engine (Ref. 15). The AngloFrench Concorde supersonic transport had a pair of two-dimensional inlets mounted under each wing with each inlet feeding an engine (Refs. 16 and 17). Both aircraft reached speeds in excess of Mach 2.0. An attractive feature of two-dimensional inlets for these aircraft was that variable-geometry elements, such as rotating ramps, could be more easily integrated into the inlet than for axisymmetric inlets. The inlets incorporated a throat slot at the end of the external diffuser ramps to reduce the adverse effects of shock/ boundary layer interactions and provide a bypass of flow to allow proper matching of flow for the engine. The two-dimensional inlet was an attractive option for supersonic transport aircraft studies in the 1990's as part of NASA's High-Speed Research Program (Ref. 18). The inlet concept centered on a twodimensional, bifurcated duct inlet in which two external-compression ramp systems mirrored about a plane-of-symmetry fed a single duct leading to the engine. That project involved a cruise speed of Mach 2.5, which meant the inlet also incorporated internal supersonic compression. For flight below Mach 2.0, the two-dimensional inlet remains a viable option. The conceptual study by the Boeing Company suggests a two-dimensional inlet as an option (Ref. 1).

In addition to external compression of supersonic flow about axisymmetric or two-dimensional surfaces, it is possible to compress supersonic flow about "three-dimensional" surfaces through the process of streamline tracing. The process involves defining a compressive flow field, establishing a curve from which the streamlines originate, and then tracing the streamlines through the flow field to define the compression surface. This process has been used to develop inlet surfaces for hypersonic speeds. Mölder and Szpiro studied an inlet based on an axisymmetric, flow field proposed by Busemann in which the supersonic inflow and outflow are uniform and directed along the axis-of-symmetry (Ref. 19). The Mach waves isentropically compress the flow inward toward the axis-of-symmetry. An oblique, conical shock then turns the flow and the shock is cancelled at the inlet surface to yield axial, uniform outflow. The Taylor-Maccoll conical equations and oblique shock relations provide an analytic solution for the flow field. The streamline-tracing technique has been applied by various researchers to develop inlets for hypersonic missiles and aircraft (Refs. 20 and 21). The technique allows the generation of a wide variety of surface shapes depending on the shape of the curve from which the streamlines originate. The surfaces are potentially "three-dimensional" surfaces if the generated surfaces are nonplanar and asymmetric. Thus, streamline tracing can facilitate improved integration of the inlet with the aircraft, which is of increased importance at hypersonic speeds, but may also be of importance for supersonic speeds for which the reduction of sonic boom effects is desired.

At speeds below Mach 2.0, it is possible to generate streamline-traced surfaces for external supersonic compression. However, the oblique shock is replaced with a stronger shock that yields subsonic outflow. The use of streamline tracing for external-compression inlets has been limited. Konscek studied the use of streamline tracing for Mach 2.5 flight as part of the NASA High-Speed Research Program in the late 1990's and a patent was released in 2004 (Ref. 22). A parallel effort at NASA resulted in the so-called "Parametric Inlet", which used an external-compression supersonic diffuser that 
compressed the flow isentropically by turning the flow toward the axis-of-symmetry. The curve from which the streamlines originated was located in the throat and had the shape of a partial co-annular section. This yielded flat sidewalls which did not contribute to the isentropic compression. The Parametric Inlet underwent an extensive design and analysis process involving CFD and a wind-tunnel model was fabricated and tested in 2004 (Ref. 23). A "three-dimensional” inlet concept derived from streamline tracing was studied by Vinogradov and Stepanov for a Mach 2.0 supersonic business jet (Ref. 24).

The focus of this paper is to investigate inlet concepts suitable for supersonic commercial flight below Mach 2.0 and develop the computational tools for the design and analysis of those inlet concepts. Over the past 60 years, various methods and tools have been applied for the design of supersonic inlets. Analytic methods for shock waves and compressible flow such as documented in the NACA Report 1135 formed a starting point for many of the methods (Ref. 13). Empirical methods derived from wind-tunnel and flight studies provided information on such things as shock stand-off distances and total pressure loss through subsonic ducts (Refs. 25 and 26). Such methods were coded into computational tools such as the US Air Force Level II Installation Code, the US Navy NIDA Code, and the NASA Inlet Performance Analysis Code (IPAC) (Refs. 27 to 29). The InletMOC and LercInlet codes incorporated the method of characteristics for planar compressible flow for the analysis and design of external and internal supersonic diffusers (Refs. 30 to 31). Forms of LercInlet are still being used despite being over 40 years old. The LAPIN code solves the unsteady, quasi-one-dimensional Euler equations to analyze steady and unsteady flow within mixed-compression inlets (Ref. 32). The methods of computational fluid dynamics (CFD) have been applied to solve the unsteady, three-dimensional, viscous flow through supersonic inlets (Ref. 23). The increased fidelity and flow field detail possible with CFD methods requires greater complexity and time for the analysis.

The present work has the objective of retaining the capability of the various past tools while updating and documenting the coding and methods. The objective is to provide a capability to design and analyze traditional inlet types, such as the axisymmetric and two-dimensional inlets, as well as, develop tools to design and analyze newer inlet concepts, such as the streamline-traced inlets. The work has resulted in the computational tool named SUPIN (SUPersonic INlet design and analysis tool). SUPIN is being written in Fortran 95. The intent has been to provide a tool to design inlet geometry and perform analysis of an inlet using a small set of key input factors. The methods used are analytic, empirical, and numerical. While some compressible flow relations and method of characteristics solutions yield planar flow fields, much of the analysis is based on a one-dimensional representation of the inlet flow. Thus, the methods are of low fidelity. However, this allows an almost instantaneous computational time, which is beneficial for use in aircraft system studies that require basic supersonic inlet performance data and geometry properties (Ref. 33). Yet, we wish to retain the option to launch into higher-fidelity analysis of the inlet using CFD methods. SUPIN has capabilities to automatically generate surface grids that can be directly used for the generation of computational grids needed for analysis using CFD methods. When an axisymmetric or two-dimensional flow analysis is appropriate, SUPIN can create a planar grid at the symmetry plane of the inlet that can be directly input to CFD codes.

This paper describes the models and methods for the geometry modeling, aerodynamic analysis, and design of supersonic external-compression inlets as implemented into the SUPIN tool. The types of inlets modeled within SUPIN are discussed in the next section and include: the axisymmetric outward-turning inlet, the two-dimensional single-duct inlet, the two-dimensional bifurcated-duct inlet, and the streamlinetraced inlet. These types encompass not only the traditional inlet types, but allow for modeling of newer inlet concepts. The modeling divides the inlet flow field into parts that allow natural segmentation of the modeling tasks. Section III discusses the parts of the inlet flow field. Section IV discusses the freestream and approach flow parts of the flow field, which provide the upstream boundary conditions for the inlet design and analysis problem. Section V discusses the engine face, which provides the downstream boundary conditions. Section VI discusses the external supersonic diffuser, which is an essential part that 
defines the character of the inlet. The nose is also discussed within this section. Section VII discusses the cowl lip and cowl exterior, which characterize the capture area and external drag of the inlet. Section VIII discusses the internal ducting of the inlet consisting of the throat and subsonic diffuser through which flow is subsonic leading to the engine face. Section IX discusses the primary performance measures calculated for the inlet, which include the flow rates, total pressure recovery, and drag. The use of SUPIN for the design and analysis of inlets is discussed in Section X and includes information on the input and output files of SUPIN and the modes of using SUPIN for geometry creation, design and sizing, and analysis. The output files include surface and planar grids usable for CFD analysis. Section XI presents some results of several design studies using SUPIN and results generated with planar CFD analyses that provide some verification of the methods used within SUPIN.

\section{Inlet Types}

The development of a computational tool for the design and analysis of supersonic externalcompression inlets is made simpler by limiting the possible inlets to a set of four inlet types: the axisymmetric outward-turning inlet, the two-dimensional single-duct inlet, the two-dimensional bifurcated-duct inlet, and the Busemann streamline-traced inlet. Figure 1 shows the four inlet types with each inlet cut along its vertical plane of symmetry. SUPIN does include a fifth inlet type of the axisymmetric pitot inlet; however, it is not considered an external-compression inlet since it does not have an external supersonic diffuser. Further, the poor performance of the pitot inlet at Mach numbers above Mach 1.6 does not make it an attractive inlet choice for the present work. The set of four inlet types encompass many of the traditional inlets and can be used as baseline inlets or initial concepts for inlet design studies. The streamline-traced inlet type has a number of factors that allow a wide variety of shapes that may integrate better with an aircraft.

The geometry of the four inlet types are all constructed from planar geometric operations. The surfaces of the axisymmetric, outward-turning inlet are constructed from extruding the planar profile of the centerbody and cowl about the axis-of-symmetry. Much of the two-dimensional inlet is constructed from extruding the planar profile into the cross-stream or $z$-coordinate direction. The subsonic diffuser of the two-dimensional inlets transition from a rectangular cross-section to a circular cross-section; however, each cross-section is described by a super-ellipse defined within a reference plane. Even the threedimensional surfaces of the streamline-traced inlet are generated by defining planar profiles at circumferential planes coincident with the circumferential planes of the axisymmetric Busemann flow field. This basis of planar construction greatly simplifies the geometry modeling methods while allowing a wide variety of inlet shapes. Further details on the geometry modeling will be discussed in the sections below.
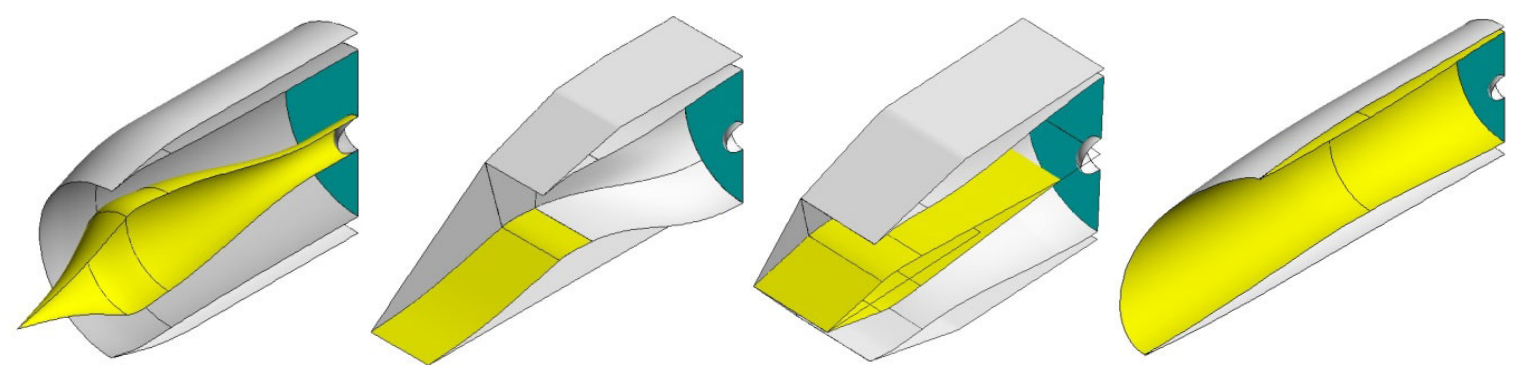

Figure 1.-Set of supersonic external-compression inlet types (left to right: axisymmetric outward-turning, two-dimensional single-duct, two-dimensional bifurcated, and streamline-traced). 

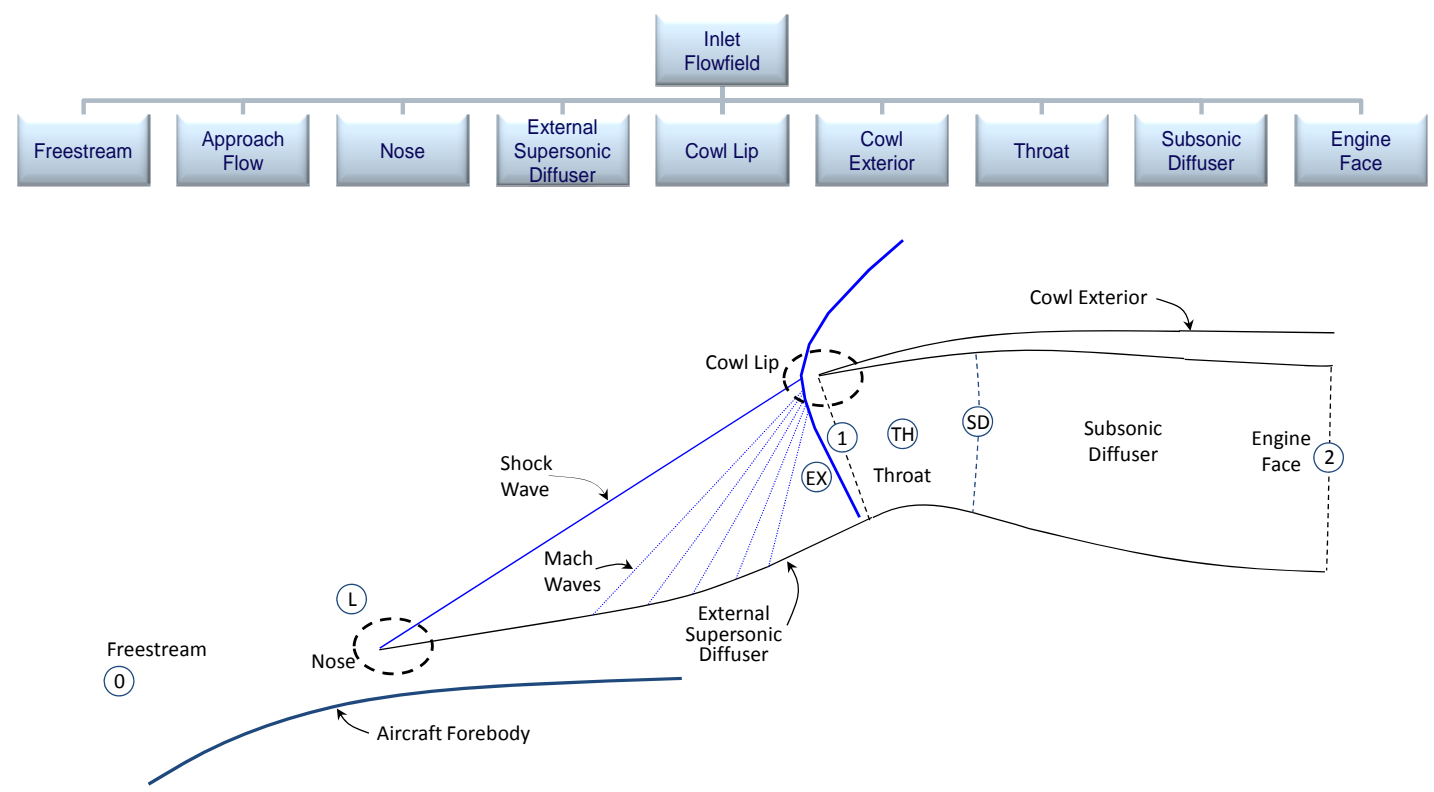

Figure 2.-Parts of the supersonic external-compression inlet flowfield.

\section{Parts of the Inlet Flowfield}

The inlet flowfield includes the streamtube of airflow that extends from the freestream to the engine face while passing over and through the inlet. This flow field is divided into parts which facilitate the geometric modeling and aerodynamic analysis of the inlet. Figure 2 shows the parts for an externalcompression inlet along with a schematic of an inlet showing the general location of the parts.

The numbers or letters within circles indicate key stations within the flowfield. The stations are mostly located at boundaries between the parts. The numbers correspond to standard stations for an inlet for a turbo-fan engine (Ref. 34). Stations 0, 1, and 2 correspond to the freestream, cowl lip entrance, and engine-face stations, respectively. The stations with letters correspond to additional stations that further define the flow field. These are defined in the sections below in discussion of the individual parts of the inlet.

\section{Freestream and Approach Flow}

The freestream and approach flow parts form the upstream boundary to the inlet design and analysis task. The freestream is described by uniform flow properties ahead of the aircraft at station 0 . This includes the Mach number and angle-of-attack of the aircraft and the static pressure and temperature of the freestream, which can be determined from the standard atmosphere and a specified altitude. The specifications for the freestream are assumed to be explicitly defined as part of the mission analysis and operating point for which the inlet is to be designed.

The approach flow considers the effects on the inlet streamtube as it washes over the forward parts of the aircraft prior to encountering the inlet. The approach flow effects occur between stations 0 and $\mathrm{L}$ with uniform and steady conditions at station L. The approach flow models possible installation effects for the inlet as part of the aircraft. The model assumes the flow encounters a combination of oblique shocks, conical shocks, and Prandtl-Meyer expansions. The result is the uniform flow conditions at station L. 


\section{Engine Face}

The engine face forms the downstream boundary to the inlet design and analysis task. It is assumed that the engine size and engine operating point to which the inlet is to be designed are known. Here it is assumed the engine face has a circular cross-section corresponding to a gas turbine engine and the engineface dimensions include the engine-face diameter $\left(D_{E F}\right)$. A spinner may exist to cover the engine-face hub. If a spinner exists, it is assumed that the hub diameter, spinner length, and planar profile shape are known. The spinner can be modeled to have a conical, circular, or elliptical profile. For an axisymmetric, outward-turning inlet, the centerbody surface is assumed to cover the spinner and match up to the hub diameter. The inlet examples shown in Figure 1 have spinners with elliptical profiles. For axisymmetric inlets, the axis of the engine is assumed to coincide with the axis-of-symmetry of the inlet. For twodimensional bifurcated inlets, the engine axis coincides with the line of intersection of the two symmetry planes. For two-dimensional, single-duct inlets and streamline-traced inlets the engine axis is on the plane of symmetry, but it can be moved vertically to adjust the subsonic diffuser shape. For the inlet design and analysis task, it is assumed that the engine flow rate is specified in some form. Section IX will discuss further the engine flow rate.

\section{Nose and External Supersonic Diffuser}

The nose is the start of the external supersonic diffuser. The nose is a point for an axisymmetric outward-turning inlet and a linear edge for the two-dimensional inlets. The streamline-traced inlet does not have a nose, but rather the cowl lip defines the leading edge of the external supersonic diffuser. While it is common for supersonic inlets to have sharp noses and leading edges, a nose with a circular profile can be modeled.

The external supersonic diffuser compresses the supersonic flow external to the interior duct of the inlet from station L to station EX. The compression involves a number of stages in which each stage turns the flow into itself with the creation of shock or Mach waves. Shock waves are generated when the stage involves sudden turning. Mach waves are created when the stage involves gradual turning. Station EX is located just upstream of the strong terminal shock that changes the inlet flow to subsonic. The flow properties at station EX are the one-dimensional, mass-averaged properties of the supersonic flow at the end of the external compression. These properties are used as the upstream conditions for the normal shock calculations that determine the properties at station NS, which is downstream of the terminal shock. The inlet is designed for critical conditions for which the terminal shock is located at station 1 , which is the entrance to the internal ducting of the inlet. Thus, at the design point, stations NS and 1 are coincident and have the same flow properties. Thus, the external supersonic diffuser extends from the nose to station 1 . The planar surface at station 1 is defined as the plane passing through the cowl lip and perpendicular to the external supersonic diffuser. The two sub-sections below discuss the specific design methods for the external supersonic diffusers.

\section{A. Axisymmetric and Two-Dimensional External Supersonic Diffusers}

The axisymmetric outward-turning inlet has an external supersonic diffuser consisting of an axisymmetric centerbody that turns the flow outward from the axis-of-symmetry to create conical shocks and Mach waves. The two-dimensional inlets turn the flow along planar ramps or curved surfaces of a specified width. The two-dimensional inlets also include sidewalls to contain the compression on the external supersonic diffuser. The leading edge of the sidewall is assumed to be a straight line from the nose to the cowl lip.

The external supersonic diffuser is designed so that the shock and Mach waves created on each stage pass through focal points. Figure 3 is a schematic showing an external supersonic diffuser with three stages that creates shock waves that pass through a focal point near the cowl lip. While Figure 3 shows all three waves with the same focal points, each wave can have its own focal point. The focal points are 


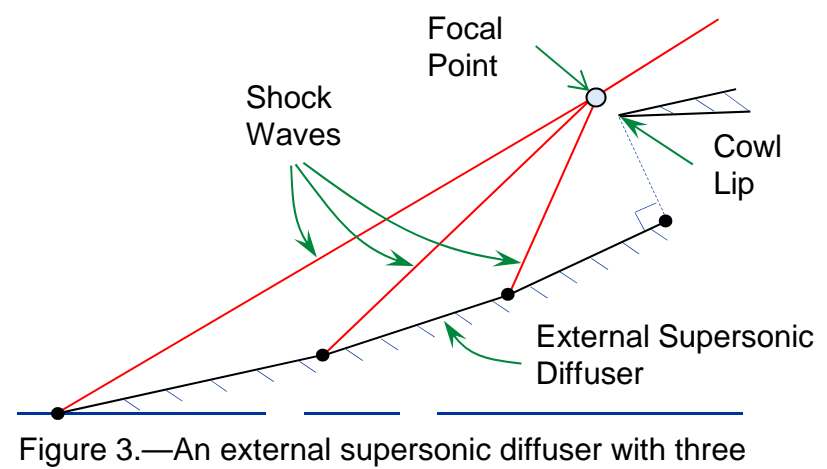
stages with oblique shocks with a common focal point.
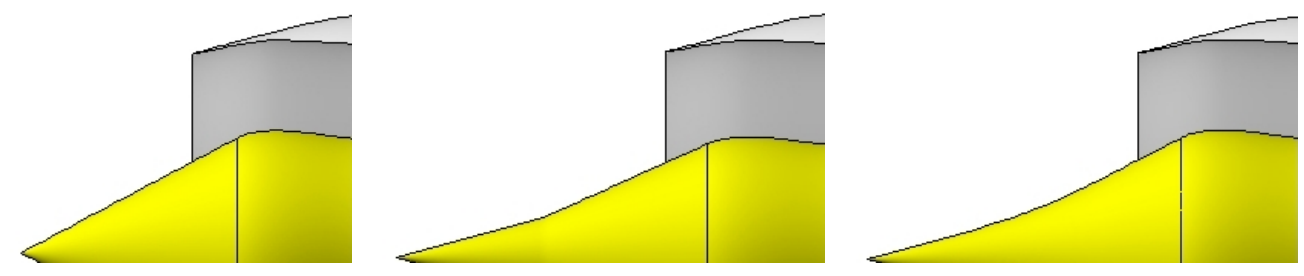

Figure 4.-Axisymmetric external supersonic diffusers with one (left), two (middle), and three (right) stages.

placed with respect to the cowl lip. The so-called "shock-on-lip" condition involves placing the focal points coincident with the cowl lip. This results in zero supersonic spillage, which maximizes the airflow into the inlet. Placing the focal points above the cowl lip results in supersonic spillage, which may be advantageous for the stability of the inlet over its range of operations.

Each stage of the external supersonic diffuser is characterized by a change in surface angle that results in the flow being turned. A stage consisting of a conical or ramp surface will create a shock wave. Compressible flow equations such as oblique shock and conical shock equations can be used to solve for the shock wave angles and change in flow properties for the stage (Refs. 8 and 13). Method-ofcharacteristic numerical methods can be used to solve more complex conical shocks and Mach waves through the stage (Ref. 31). Knowing the wave angles and focal point locations, the start and end of the stages can be determined. The analytic and numerical flow solutions provide the change in the total pressure through the stages.

SUPIN provides the capability to explicitly specify the flow turning angles and start and end locations of the stages or to determine these quantities using design operations. SUPIN can design axisymmetric external supersonic diffusers with a single cone, two cones (bi-conic), and three stages in which the second stage is curved with an isentropic compression of Mach waves. The design methods require specification of the desired Mach number at the end of the external supersonic diffuser, which is at station EX and assumed to be at station 1 .

SUPIN can design two-dimensional external supersonic diffusers with one, two, or three stages. For a three-stage diffuser, the second stage can either be a ramp or be curved to provide for isentropic compression using Mach waves. For two-dimensional diffusers consisting of ramps, SUPIN provides a method to search for the ramp angles that result in the lowest total pressure loss for the diffuser. This solution corresponds to the observation of Oswatitsch that the total pressure loss through the external supersonic diffuser is minimized when the losses through each shock wave are equal (Ref. 9).

Figure 4 shows three external-compression supersonic diffusers for axisymmetric inlets with one, two, and three stages. The middle diffuser is bi-conic. The diffuser on the right has an isentropic, curved second stage. As the number of stages increases, the total pressure losses decrease; however, the diffuser becomes longer. The design study below will provide more details on the properties of the external supersonic diffuser designs. 


\section{B. Streamline-Traced External Supersonic Diffusers}

The external supersonic diffuser for the streamline-traced inlet takes on a separate character than the multi-stage diffusers discussed. The streamline-traced diffuser is considered to consist of one stage involving isentropic compression. The nose and cowl lip are indistinguishable such that the leading edge of the diffuser is modeled as the cowl lip.

The design of the diffuser starts with an axisymmetric Busemann flow field characterized by the inflow and outflow Mach numbers. The Taylor-Maccoll equations are solved for the axisymmetric conical flow field about a focal point (Refs. 8 and 14). Figure 5 shows an example of the conical flow field. The flow is uniform at the inflow and outflow and the direction is axial. The inflow Mach number corresponds to the Mach number at station $L, M_{L}$. The design method involves specifying the desired outflow Mach number. An iteration scheme is performed on the angle of the shock wave to arrive at the desired inflow Mach number for the specified outflow Mach number.

The surface of the diffuser is formed by tracing streamlines through the Busemann flow field. The process involves defining a tracing curve within the outflow and then integrating the streamlines in the upstream direction through the flow field. The tracing curve is a closed curve defined on a plane that is perpendicular to the flow. The tracing curve is built of separate super-ellipses for the top and bottom. The paper by Konscek presents one of the earliest applications of the super-ellipse for inlet design (Ref. 35). The super ellipse is characterized by the lengths of the semi-major $\left(a_{S T}\right)$ and semi-minor axis $\left(b_{S T}\right)$ and a super-ellipse parameter $\left(p_{S T}\right)$. A parameter value of $p_{S T}=2$ indicates an ellipse. The curve approaches a rectangle as the parameter is increased. The top and bottom sections of the tracing curve share the same semi-major axis length, but can have different values of the semi-minor axis length and parameter. Figure 6 shows two examples of tracing curves. The tracing curve on the left consists of circular arcs for the top and bottom sections. The curve on the right has a circular arc for the top section and a superelliptic curve for the bottom with the parameter equal to $p_{\text {STbot }}=10$. The tracing curves are defined in a local coordinate system in which the center is on the $x$-z plane but can be translated in the $y$-direction by a value $\Delta y_{S T}$. This approach for defining the tracing curves and placing it with respect to the axis-ofsymmetry of the Busemann flow field provides a capability to generate a wide variety of shapes for the external supersonic diffuser.

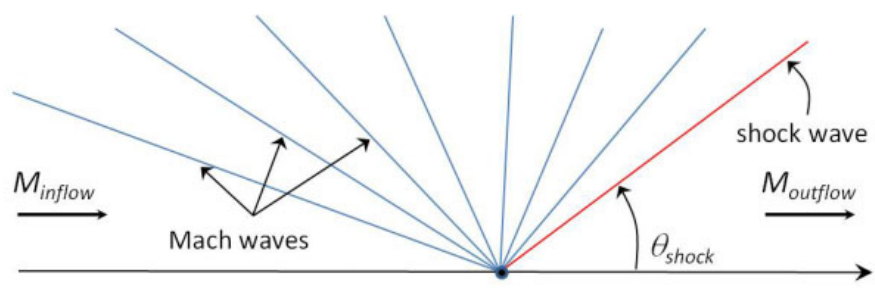

Figure 5.-Axisymmetric Busemann flow field.

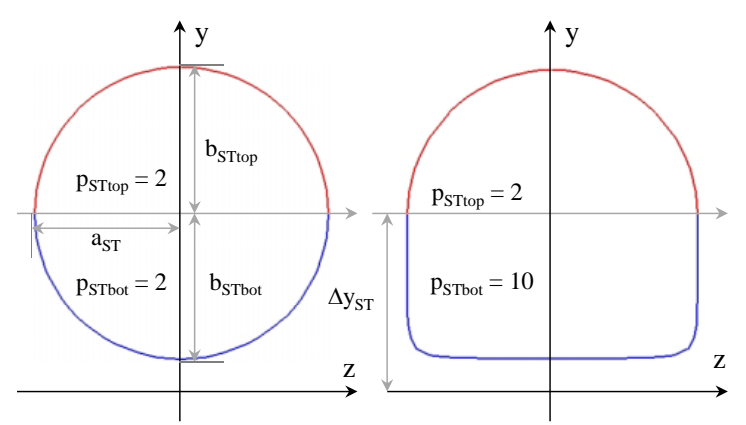

Figure 6.-Tracing curves for two streamline-traced. Inlets. 


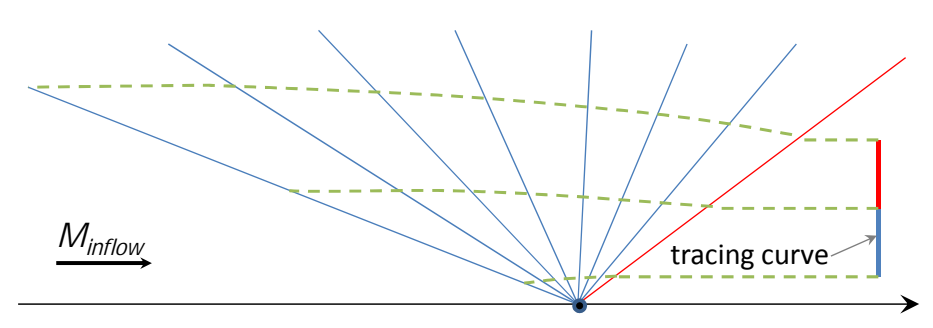

Figure 7.-Integration of streamlines from the tracing curve.

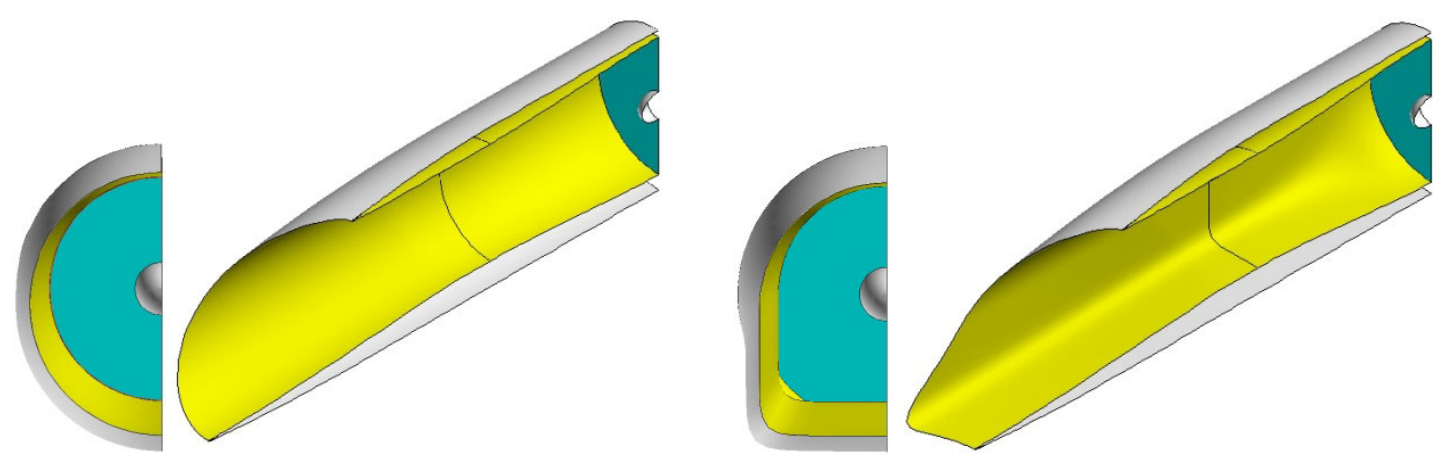

Figure 8.-Examples of streamline-traced inlets with the tracing curves of Figure 6.

The tracing curve is placed in the uniform outflow of the Busemann flow field. The streamlines are then created by starting at points on the tracing curve and integrating the local velocity field in the upstream direction. Figure 7 shows an example of the creation of the streamlines (shown as dashed lines). Each point on the tracing curve is associated with a circumferential angle of the axisymmetric flow. Thus the integration of each streamline is a planar integration problem.

The shape of the tracing curve and the placement of the tracing curve with respect to the axis-ofsymmetry provides for a variety of diffuser shapes. For an external supersonic diffuser, the tracing curve is placed away from the axis-of-symmetry such that the streamlines will not contain the focal point of the Busemann flow field. Figure 7 shows the tracing curve "above" the axis-of-symmetry. The tracing curve can also be placed below the axis-of-symmetry. Figure 8 shows two examples of streamline-traced inlets created from the tracing curve shapes of Figure 6. In these examples, the tracing curves were placed below the axis-of-symmetry. This created a shape with a "cut-out" at the top of the inlet.

\section{Cowl Lip and Cowl Exterior}

The cowl lip is the start of the internal ducting of the inlet and the location of the cowl lip determines in part the amount of the inlet streamtube flow that is captured and delivered to the engine. The cowl exterior starts at the cowl lip exterior and encloses the inlet to provide a surface for which the cowl drag can be estimated.

The cowl lip coordinate is either specified or determined as part of the sizing operation. For an axisymmetric inlet, the radius of the cowl lip corresponds with the circular shape of the capture area. For the two-dimensional inlets, the height of the cowl lip corresponds with the rectangular shape of the capture area and the specified width of the external supersonic diffuser. For the streamline-traced inlet, the cowl lip coordinates vary circumferentially and the locus of the points forms the outline of the capture area.

The profile of the cowl lip can be sharp, circular, or elliptical. Figure 9 shows examples of each profile shape along with the geometric factors. The cowl lip is characterized by the surface angles of the cowl lip interior and cowl lip exterior. The angle of the cowl lip interior influences the subsonic diffusion at the entrance of the throat. The angle of the cowl lip exterior influences the supersonic flow at the start of the cowl exterior, which affects the cowl wave drag on the cowl exterior. The cowl lip angles should 

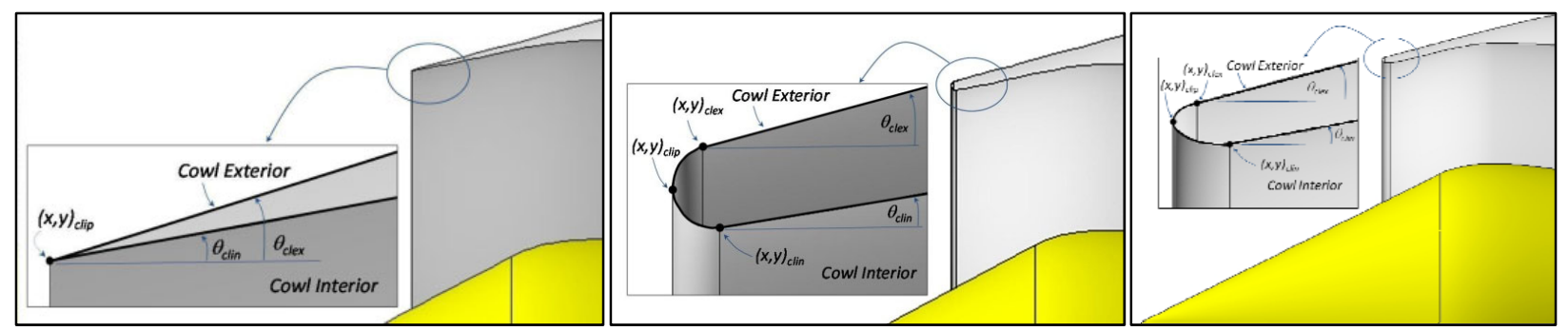

Figure 9.-Cowl lip shapes (left-right: sharp, circular, and elliptical) (right) cowl lips.
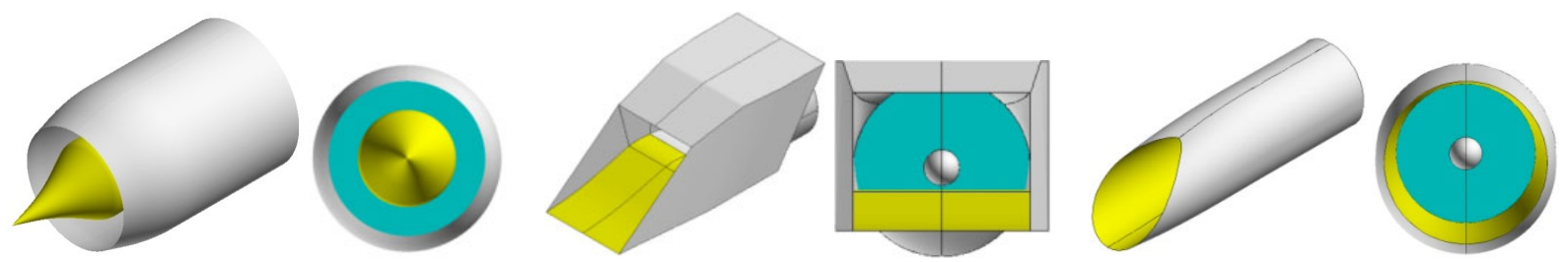

Figure 10.-Cowl exteriors for the axisymmetric (left), two-dimensional (center), and streamline-traced (right) inlets.

align roughly to the angle of the flow at the cowl lip to minimize the generation of exterior shocks, especially strong shocks. The cowl lip exterior angle should be $3^{\circ}$ to $5^{\circ}$ greater than the cowl lip interior angle to allow some structural bulk for the cowl lip.

The cowl exterior is washed by the portion of the inlet streamtube that does not enter the internal ducting of the inlet. The cowl exterior starts at the cowl lip exterior. The initial angle of the cowl exterior surface is equal to the angle of the cowl lip exterior. The end of the cowl exterior is set to the same axial coordinate as the engine face with the radial or cross-stream coordinates placed a certain factor of the engine-face radius. The cowl exterior surface is then formed between these two end coordinates. The cowl exteriors for the axisymmetric and streamline-traced inlets use a curved surface, while the cowl exteriors for the two-dimensional inlets are faceted planes. The sides of the cowl exterior for the twodimensional inlets require specification of an exterior sidewall angle. This simple model only requires a few input factors, but creates a realistic surface for which the cowl wave drag can be calculated. Figure 10 shows examples of the cowl exteriors for the axisymmetric, two-dimensional, and streamline-traced inlets. The front views show the amount of axially-projected area of the cowl exterior that contributes to the cowl wave drag.

\section{Throat and Subsonic Diffuser}

The throat and the subsonic diffuser form the internal ducting of the inlets. The throat is the forward portion of the ducting and turns the subsonic flow downstream of the terminal shock into the entrance of the subsonic duct. While the throat and subsonic diffuser are both intended to be subsonic ducts, the throat may contain the terminal shock in the case of super-critical inlet flow. However, the modeling assumes that at the end of the throat at station SD, the flow is fully subsonic for entrance to the subsonic diffuser.

The geometry model for the throat assumes the coordinates and angles at the inflow at station 1 are known. A "break angle" for the centerbody at station 1 can be specified in the inputs to indicate a discontinuous slope in the centerbody surface. The coordinates of the centerbody at station SD are specified in the inputs with respect to the centerbody coordinates at station 1 . The angles for both the centerbody and cowl interior at station SD are also specified in the inputs. A smooth curve is created for the profile of the centerbody in which the specified end-coordinates and angles are matched. The curve for the profile of the cowl interior is created in a similar manner; however, the cross-sectional areas at stations TH and SD are used to determine the cowl coordinates at these stations. Station TH is an 

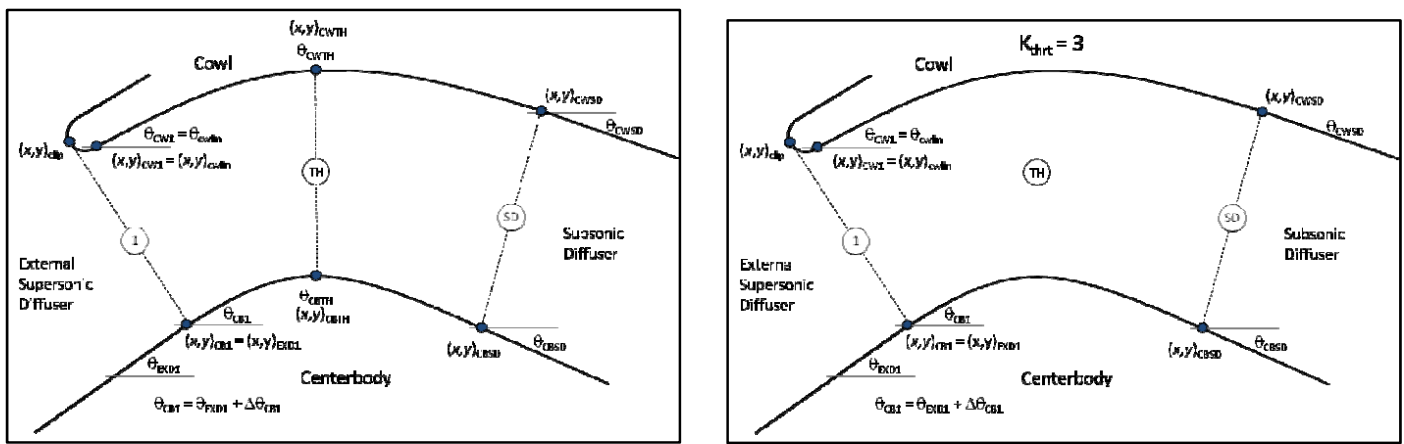

Figure 11.-Geometry models for the throat.

intermediate station. Three options exist for specifying the cross-sectional areas: 1) the area ratios between stations TH and 1 and stations SD and TH can be specified in the inputs, 2) a Mach number at station TH and the area ratio between stations SD and TH can be specified, and 3) the area ratio between stations SD and 1 can be specified. For option 2, the area ratio between stations TH and 1 is computed such as to yield the specified Mach number at station TH. With the cross-sectional areas at stations TH and SD known, the coordinate of the cowl can be calculated. This calculation assumes that the crosssectional shape is the same as at station 1 . Thus, an axisymmetric inlet has a co-annular shape and the two-dimensional inlets have a rectangular shape. Figure 11 shows planar schematics of the throat. The drawing on the left is used for options 1 and 2. The drawing on the right is used for option 3 . For option 3 , station TH is not defined.

For the streamline-traced inlets, the throat is modeled as a constant-area section that has the same cross-sectional shape as the tracing curve. The cross-sections are perpendicular to the axis-of-symmetry. The length of the throat is specified in the inputs.

The subsonic diffuser connects the cross-section at the end of the throat with the engine face. The length of the subsonic diffuser can be directly specified as an input or computed to match a specified equivalent conical angle.

For axisymmetric inlets, the annular cross-section at the end of the throat provides a straight-forward blending to the annular cross-section at the engine face. The planar profile of the centerbody assumes a smooth curve intersecting a cylindrical hub some distance $\left(L_{C E X}\right)$ upstream of the engine face. This models a centerbody that may translate axially on the hub. The planar profile of the cowl is determined based on the area distribution through the subsonic diffuser. The planar profiles are then extruded about the axis-of-symmetry to create the surfaces of the subsonic duct. The image on the left of Figure 12 shows the geometric factors and example geometry for the axisymmetric subsonic duct.

For two-dimensional inlets, the subsonic diffuser is required to transition from a rectangular crosssection at the end of the throat to a circular cross-section at the engine face. This is performed by blending a distribution of rectangular and super-elliptic cross-sections. Both distributions use the same area variation. The image on the right of Figure 12 shows an example of the subsonic diffuser for a twodimensional, single-duct inlet. The image shows a cut at the symmetry plane.

The subsonic diffuser for the streamline-traced inlet uses super-ellipses for the cross-sections through the axial length of the subsonic diffuser. The lengths of the semi-major and semi-minor axes and the value of the super-ellipse parameter are blended from the values at station SD to the values required to match the circular shape of the engine face at station 2. The cross-section at station SD matches the shape of the tracing curve. The cross-sections through the subsonic duct are all perpendicular to the $x$-axis. 

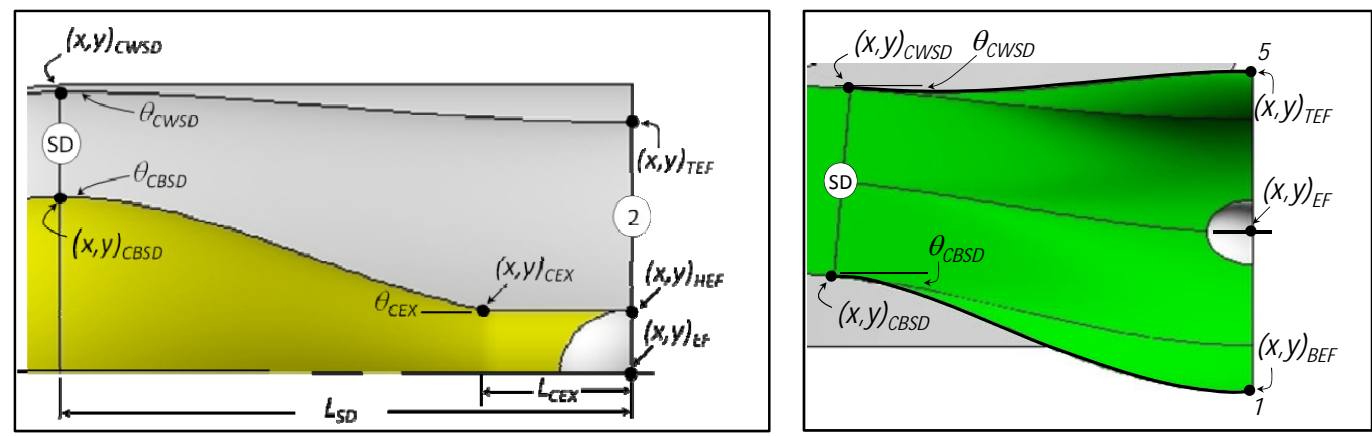

Figure 12.-Subsonic diffuser models for the axisymmetric outward-turning inlet (left) and two-dimensional, single-duct inlet (right).

\section{Inlet Performance}

The aerodynamic performance of the external-compression supersonic inlet is characterized within SUPIN by the flow rates, total pressure recovery, and drag of the inlet. This section discusses each of these performance measures and the methods used to compute them. Other inlet aerodynamic information is certainly of interest for supersonic inlets, such as boundary layer properties, engine-face total pressure distortion, and buzz stability limits; however, SUPIN currently has no models for these properties.

\section{A. Inlet Flow Rates}

The inlet captures air from the freestream and delivers it to the engine. Figure 13 shows an example of the airflow about a two-dimensional inlet. The rate of flow entering the inlet is denoted as $W_{1}$ with $A_{1}$ as the cross-sectional area at station 1 . The lower dashed line extending upstream from the cowl lip indicates the bounding streamline of the streamtube entering the inlet. At station $\mathrm{L}$, the rate of flow is indicated by $W_{L}$ with a cross-sectional area of $A_{L}$. For continuity, $W_{L}=W_{1}$. The solid horizontal line indicates the cowl lip height that defines the capture area, $A_{\text {cap }}$. The image shows the capture streamline being turned by the shock waves such that $A_{L}<A_{\text {cap }}$. The potential airflow that does not enter the inlet is considered spillage and is shown flowing past the cowl exterior with the flow rate of $W_{\text {spillage. }}$ The rate of flow entering the engine is $W_{2}$ with a cross-sectional area of $A_{2}$.

The rate of flow is defined as

$$
W=\frac{p_{t}}{\sqrt{T_{t}}} A \phi
$$

where $\phi$ is the flow function or mass flow parameter expressed as

$$
\phi=M\left(\frac{\gamma}{R}\right)^{1 / 2}\left(1+\frac{\gamma-1}{2} M^{2}\right)^{-(\gamma+1) / 2(\gamma-1)}
$$

A theoretical capture flow rate can be defined as

$$
W_{\text {cap }}=\frac{p_{t L}}{\sqrt{T_{t L}}} A_{\text {cap }} \phi_{L}
$$

where $A_{\text {cap }}$ is a reference area called the capture area. The capture area is defined as the forward projection along the inlet axis $(x)$ of the area defined by the cowl lip and any sidewalls edges. For an axisymmetric inlet, the capture area is bounded by a circle. For the two-dimensional inlets, the capture area is bounded 


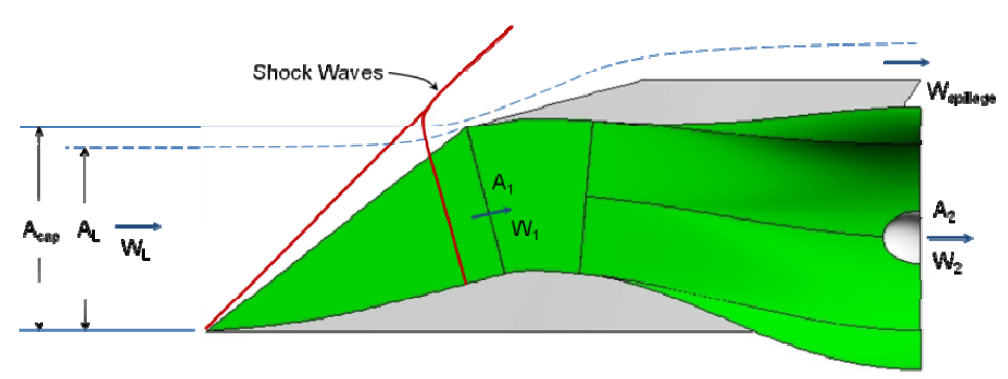

Figure 13.-A streamtube for a two-dimensional inlet flowfield.

by a rectangle defined by the cowl lip and sidewall edges. For the streamline-traced inlet, the capture area can be a variety of shapes and is defined by the coordinates of the cowl lip about the circumference of the external supersonic diffuser. The theoretical capture flow rate is the maximum supersonic flow that can be accepted into the inlet and serves as the reference flow rate.

For the external-compression inlets of interest in this work, it is assumed that no flow is extracted from the inlet streamtube due to bleed, bypass, or leakages and no flow enters the streamtube due to jets or auxiliary inlets. This simplification is consistent with the desire to keep the inlets for Mach 1.6 to 2.0 as simple as possible. This simplification will eventually be relaxed within SUPIN as more complex analysis capabilities are introduced to model bleed and bypass. Thus, flow continuity is assumed through the inlet streamtube,

$$
W_{L}=W_{1}=W_{2}
$$

The amount of the theoretical capture flow that does not enter the inlet is considered "spilled" past the inlet and represents a loss of the maximum flow that the inlet can capture. This spillage flow is denoted as $W_{\text {spillage }}$ and flow continuity can be expressed as

$$
W_{\text {cap }}=W_{L}+W_{\text {spillage }}
$$

A normalized flow continuity equation can be obtained for the inlet by combining Equations (4) and (5) and normalizing by $W_{\text {cap }}$ to yield

$$
\frac{W_{2}}{W_{\text {cap }}}=1-\frac{W_{\text {spillage }}}{W_{\text {cap }}}
$$

Equation (6) can be used to either size the capture area of the inlet or determine the rate of spillage for an inlet. The sizing of the inlet involves determining $W_{2}$ and estimating $W_{\text {spillage }}$ and then solving Equation (6) for $W_{\text {cap. }}$. From $W_{\text {cap }}$, the capture area $A_{\text {cap }}$ can be computed using Equation (3). For a specific type of inlet of Figure 1, the dimensions of the capture cross-section can be established. For example, for an axisymmetric inlet, which has a circular capture area, the cowl lip diameter can be computed easily from the capture area. For the two-dimensional inlets which have a rectangular capture area, the height of the cowl lip can be computed from knowing the capture area and the specified width of the capture area, which is the width of the external supersonic diffuser. For the streamline-traced inlet, the capture area shape is computed from the cross-section of the stream surface at the inflow. Iterations of the semi-major axis length of the tracing curve are performed to yield the tracing curve dimensions that will match the required capture area. The spillage $W_{\text {spillage }}$ can be calculated using Equation (6) for inlet analyses for which $W_{\text {cap }}$ and $W_{2}$ are known. 
The engine flow rate $W_{2}$ can be determined from the corrected engine flow rate $W_{C 2}$. For inlet design and analysis, it is assumed that the properties of the engine are known from a mission analysis and engine sizing. These properties include the diameter of the fan face $D_{2}$ and spinner geometry such that the crosssectional area at the fan face $A_{2}$ can be determined. These properties also include the corrected engine flow rate $W_{C 2}$ or equivalently the mass-averaged Mach number at the fan face, $M_{2}$. The expression for the corrected engine flow rate is

$$
W_{C 2}=W_{2} \frac{\sqrt{\theta_{2}}}{\delta_{2}}=\frac{p_{\text {tref }} A_{2}}{\sqrt{T_{\text {tref }}}} \phi_{2}
$$

The $\theta_{2}$ and $\delta_{2}$ are the total temperature and total pressure ratios, respectively, referenced to the reference total temperature $T_{\text {tref }}$ and total pressure $p_{\text {tref }}$. The engine-face area $A_{2}$ is calculated from the circular fan face diameter minus the circular area of the spinner hub (hub/tip ratio). Thus for a given engine face Mach number $M_{2}$, Equation (7) is used to compute the corrected engine flow rate $W_{C 2}$.

If the corrected engine flow rate $W_{C 2}$ is known, then Equation (7) can be used to compute the actual engine flow rate $W_{2}$. However, Equation (7) requires estimates of the total pressure $p_{t 2}$ and total temperature $T_{t 2}$ at the engine face. Adiabatic flow is assumed through the inlet, and so, $T_{t 2}=T_{t L}$. Thus, the sizing involves an iteration of the inlet design and analysis process to gradually improve the estimation of the total pressure at the engine face.

The flow ratio is a measure of how much of the theoretical capture flow rate enters the inlet. The $W_{L}$ is normalized by the theoretical capture flow rate to form the flow ratio

$$
\text { Flow Ratio }=\frac{W_{L}}{W_{\text {cap }}}=\frac{A_{L}}{A_{\text {cap }}}
$$

The inlet is referred to as operating at full flow when $A_{L}=A_{\text {cap }}$, or the flow ratio equals unity. For subsonic flow at station $L$, the flow ratio can be less or greater than unity. For supersonic flow, the flow ratio can only be equal or less than unity. If the flow ratio is less than unity, then part of the flow that could have entered the inlet under ideal conditions is being "spilled" past the inlet.

Key operating points of an external-compression inlet can be related to the flow ratio. At the "critical" operating point, the flow ratio is at its maximum with the normal shock sitting at the cowl lip plane. If the flow ratio is less than unity, then some of the flow is spilled supersonically. This will occur if the waves of the external supersonic diffuser have focal points outside of the cowl lip. The inlet can be operated at supercritical conditions in which the terminal shock enters the inlet; however, the flow ratio remains at its maximum value. If the flow ratio is below its maximum value, then flow is spilled subsonically, which requires the terminal shock to be located ahead of the cowl lip plane to allow the subsonic flow to spill past the cowl lip.

\section{B. Total Pressure Recovery}

The total pressure recovery at the engine face for an inlet is a measure of the amount of losses through the inlet and is denoted as $\left(p_{t 2} / p_{t 0}\right)$ where $p_{t 2}$ is the mass-averaged total pressure at the engine face and $p_{t 0}$ is the total pressure at the freestream conditions. The total pressure recovery at the engine face is determined as the product of the total pressure ratios between the various stations through the inlet flow field, which is expressed as

$$
\frac{p_{t 2}}{p_{t 0}}=\frac{p_{t 2}}{p_{t S D}} \frac{p_{t S D}}{p_{t 1}} \frac{p_{t 1}}{p_{t E X}} \frac{p_{t E X}}{p_{t L}} \frac{p_{t L}}{p_{t 0}}
$$


Various methods evaluate each of the ratios on the right-hand side of the Equation (9). The ratio $p_{t L} /$ $p_{t 0}$ is evaluated as the total pressure losses through the oblique and conical shock waves of the approach flow. The ratio $p_{t E X} / p_{t L}$ is evaluated as the total pressure losses through the oblique and conical shock waves of the external supersonic diffuser. The ratio $p_{t 1} / p_{t \mathrm{EX}}$ is evaluated as the total pressure loss through the terminal shock. The ratios of $p_{t S D} / p_{t 1}$, and $p_{t 2} / p_{t S D}$ are evaluated as total pressure losses due to viscosity of the subsonic flow through the throat and subsonic diffuser, respectively (Ref. 26).

The total pressure recovery varies with respect to the flow ratio or engine flow ratio. The plot of the total pressure recovery $p_{t 2} / p_{t 0}$ with respect to the engine flow ratio $W_{2} / W_{\text {cap }}$ is called the total pressure characteristic curve or the "cane" curve due to its shape like a cane. The critical operating point is located at the "knee" of the cane curve. At sub-critical operating points, the terminal shock is pushed upstream and flow is spilled past the cowl lip. The engine flow ratio decreases; however, the total pressure recovery only varies slightly. As the flow becomes more sub-critical, the inlet will eventually experience buzz, which involves terminal shock oscillations. At supercritical operating points, the terminal shock is ingested into the inlet. The engine flow ratio cannot change, but the total pressure recovery drops sharply as the Mach numbers ahead of the terminal shock increase and losses due to shock / boundary layer interactions increase.

\section{Inlet Drag}

The inlet drag is the axial force opposing thrust that results from the operation of the inlet. The inlet drag contributions modeled within SUPIN include additive drag, cowl lip drag, and wave drag

$$
C_{D \text { inlet }}=C_{D \text { add }}+C_{D \text { clip }}+C_{D \text { wave }}
$$

The additive drag is the axial pressure force applied on the virtual surface of the inlet streamtube ahead of the cowl lip when the inlet flow ratio is less than unity. The flow field ahead of the cowl lip is integrated forward of the cowl lip to create the inlet streamtube and the static pressures are determined for each segment of the streamtube. The axial pressure force is computed from an integration of the static pressures along the streamtube surface, as of the form of Equation (11). The additive drag coefficient is normalized by the dynamic pressure at the local flow station $L$ and the theoretical capture area.

$$
C_{\text {Dadd }}=\frac{2}{\gamma A_{\text {cap }} M_{L}^{2}} \int_{L}^{1}\left(\frac{p}{p L}-1\right) d A_{x}
$$

The cowl lip drag coefficient $C_{D c l i p}$ is determined from the axial force applied on the cowl lip due to suction, sharp lip flow separation, or a blunt cowl lip (Refs. 36 and 37).

The wave drag coefficient $C_{D \text { wave }}$ is computed from the integration of the axial pressure forces caused by shock and Mach waves on the cowl exterior surface. The equation for the wave drag coefficient is similar in form to Equation (11). For the two-dimensional inlets, the static pressures on the cowl exterior are computed using oblique shock relations. This includes the shock waves generated by the sidewalls. For the axisymmetric inlet, the Mach number and pressure at the start of the cowl exterior are determined from a conical flow solution. A linearized pressure solver is then used to compute the pressure coefficient along the cowl exterior (Ref. 38). 


\section{Inlet Design and Analysis Using SUPIN}

This section discusses the use of SUPIN for the design and analysis of external-compression supersonic inlets. This includes the design and analysis modes that control how SUPIN executes and an overview of the input and output files, including the grid files created for visualization and CFD analysis.

\section{A. SUPIN Input and Output Data Files}

SUPIN is a Fortran 95 program that operates in batch mode in which an input data file is read and an output data file is created. SUPIN has been developed and executed on Microsoft Windows (Microsoft Corporation) and Linux operating systems. Typical computational times range from seconds to less than a minute. The input data file (SUPIN.in) is in the format of an ASCII text file and contains blocks of input which control and provide inputs for SUPIN. While there are some requirements for the structure of the input file, there is flexibility which results in a simple input process that is usable. The output data file (SUPIN.out) is created as SUPIN is executed and also has the format of an ASCII text file. The output data file lists the values of the inputs, coordinates, geometric properties, aerodynamic properties, and performance results of the inlet.

\section{B. Inlet Surface Grids}

SUPIN represents the geometry of the inlet by distributing grid points along the planar profiles and creating surface grids for the inlet surfaces. The coordinates of the profiles are output to the output data file. The surface grids are output in Plot3D and stereo-lithography (STL) file formats (Ref. 39). These files can then be used by grid generation methods to create volume grids useful for CFD analysis. The generation of the grid points and surfaces is performed in an automated manner. The topology and geometric properties for the inlet are implied within the geometry model. The inputs to SUPIN include desired grid spacing values at key locations within the inlet, such as, the nose, cowl lip, throat, and engine face. Likewise, in the direction normal to walls, one may want to impose grid spacing values for resolution of boundary layers within CFD analyses. SUPIN applies an algorithm to calculate the number of grid points along the surfaces that provides for the desired grid spacing. Thus, the surface grid generation is automatically performed with minimal and logical inputs from the inlet designer. Figure 14 shows some surface grids and grid spacing locations.
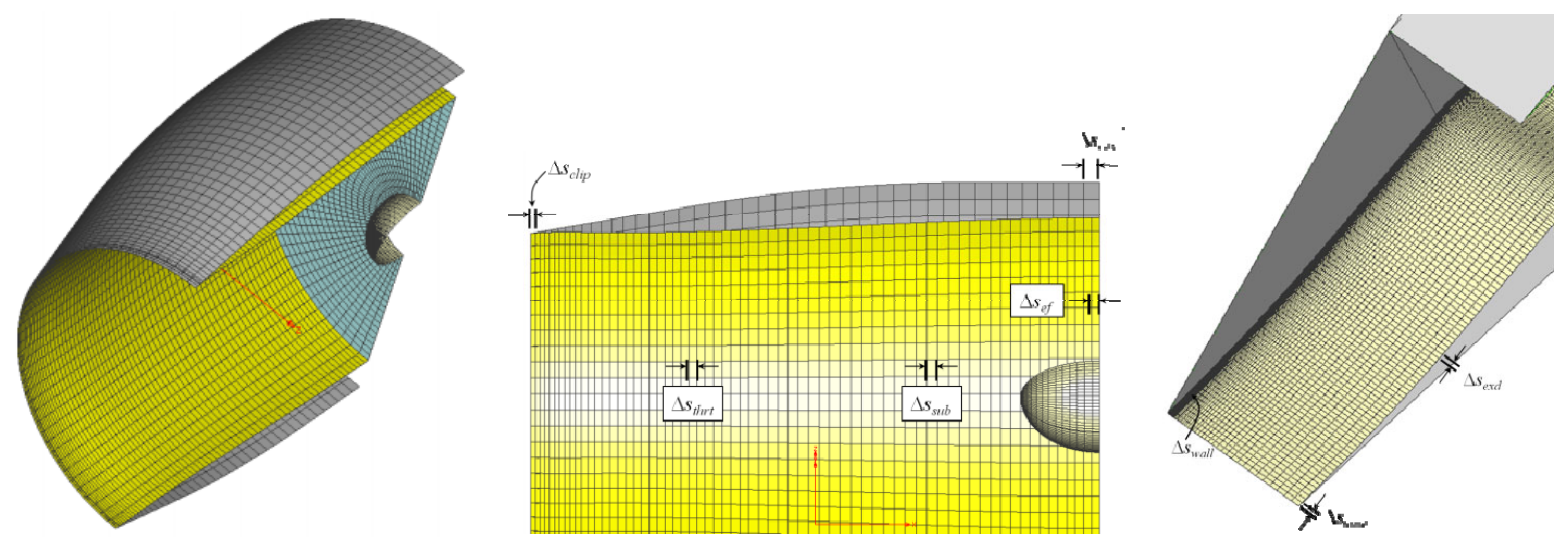

Figure 14.-Grid spacing and surface grids for the inlets. 


\section{Planar CFD Grids}

SUPIN can automatically generate a planar, multi-block structured grid for the symmetry plane of the inlet flowfield. The planar grid can be directly processed for use with a CFD code to obtain a flow solution. The planar flow solution can provide some useful information for the inlet aerodynamics since much of the inlet geometry is axisymmetric or two-dimensional and many of the methods assume axisymmetric or two-dimensional flow. The CFD flow solution can provide a verification check on the aerodynamic models within SUPIN. However, the results from a planar flow solution are limited for inlet flow fields that are inherently three-dimensional, such as the subsonic diffuser of the two-dimensional inlets and the entire flow field of the streamline-traced inlets. The inputs to SUPIN include specifications for the flow domain. The grid includes a block for the inlet outflow that attaches to the engine face. This block includes a converging-diverging nozzle with a variable nozzle throat area. This nozzle is used to impose a back-pressure for the CFD simulation and operates in an analogous manner as a choked exit plug for an inlet wind-tunnel test. The planar CFD grids are output in the Plot3D file formats.

\section{Design and Analysis Modes}

SUPIN can be executed in three modes: 1) generate the inlet geometry and surfaces from an explicit specification of the geometry factors or coordinates, 2) perform sizing and design operations for the inlet to generate the surfaces and calculate the aerodynamic performance of the inlet, and 3) generate the surfaces for a given inlet geometry and calculate the aerodynamic performance.

The first mode reads in the inputs that specify the geometry and constructs the geometry coordinates of the inlet. If specified to do so, the surface grids and planar CFD grids are be generated. No design operations are performed and no aerodynamic performance properties are calculated. One way of specifying the inlet geometry is to specify the geometric factors of the individual parts of Figure 2. Another way is to specify the centerbody and cowl profiles in terms of a collection of line, polynomial, fitted curve, and NURBS entities.

The second mode is used when one wishes to size the inlet and design the surfaces of the inlet for the freestream conditions, engine properties, and geometry factors specified in the input data file. It was discussed previously that the inlet sizing determines the inlet capture area $A_{\text {cap }}$ for a given corrected engine flow rate $W_{C 2}$ using Equation (6). This requires specifying a supersonic spillage ratio $W_{\text {spillage }} / W_{\text {cap }}$ and an initial guess for the inlet total pressure recovery $p_{t 2} / p_{t 0}$ in the input file. A fixed-point iteration is performed involving multiple analyses of the inlet to converge on the inlet total pressure recovery. Equation (7) can then be then used to compute the engine flow rate $W_{2}$ and Equation (6) used to compute $A_{\text {cap. }}$. Knowing $A_{\text {cap }}$, the dimensions of the cowl lip can be determined.

The third mode is used if one wishes to perform off-design analysis of an inlet with known geometry. SUPIN has limited off-design analysis capabilities at this time. The terminal shock is assumed to be normal and located at station 1, thus subsonic spillage is not modeled. Off-design Mach numbers can be simulated for the two-dimensional inlets with ramps and for the single-cone axisymmetric inlet. Non-zero angles-of-attack can be simulated for the two-dimensional inlets with ramps.

\section{Inlet Design Studies}

A series of design studies were performed to exercise and demonstrate the capabilities of SUPIN. All of the studies involve a basic set of specifications. The freestream properties are evaluated using the standard atmosphere at an altitude of 45,000 ft. The freestream assumes a cruise condition of Mach 1.8. No effects of an approach flow are modeled. Thus, the conditions at station $\mathrm{L}$ correspond to those at the freestream station 0. It is assumed that the engine operates at a constant corrected flow condition corresponding to an engine face Mach number of $M_{2}=0.5$. The engine face has a diameter of $3.5 \mathrm{ft}$ with a co-annular shape with a hub-to-tip ratio of 0.2. A spinner with an elliptical profile is specified. The axial length (semi-major axis) of the spinner is $0.5 \mathrm{ft}$. The radial length (semi-minor axis) of the spinner is 
$0.35 \mathrm{ft}$, which matches to the hub of the engine face. The angle of incidence of the engine face is $0.0^{\circ}$. The outflow of the external supersonic diffuser at station EX is specified to be a mass-averaged Mach number of $M_{\mathrm{EX}}=1.3$. The analyses assume the inlets are operated at the critical point with the normal shock at the cowl lip.

\section{A. Performance of the External Supersonic Diffusers}

The first study examined the variety of axisymmetric and two-dimensional external supersonic diffusers available within SUPIN. The diffusers are specified to be at zero angle-of-attack. Table 1 summarizes the results. As the number of stages increase, the surface turning angle at station $\mathrm{EX}\left(\theta_{\mathrm{EX}}\right)$ does not change significantly. While the turning for the axisymmetric diffuser is greater, the flow angles at the cowl lip $\left(\alpha_{\text {clip }}\right)$ are similar for the axisymmetric and two-dimensional diffusers. As the number of stages increase, the length of the external supersonic diffuser increases $\left(L_{\text {exd }} / D_{2}\right)$. The length of the isentropic diffuser is approximately 50 percent longer than the single-stage diffuser. The change from a single-stage diffuser to two or more stages results in a significant increase in the total pressure recovery $\left(p_{t \mathrm{EX}} / p_{t L}\right)$ and static pressure ratio $\left(p_{\mathrm{EX}} / p_{L}\right)$ for the diffuser. With a lower total pressure recovery, the single-stage diffusers are slightly smaller and result in less engine flow for the same engine corrected flow. The external supersonic diffuser for the two-dimensional bifurcated-duct inlet had the same performance as the two-dimensional single-duct inlet, and so, those results are not presented. However, the length of the external supersonic diffuser for the two-dimensional, bifurcated-duct inlet was approximately half of the length of the two-dimensional, single-duct inlet since the compression is mirrored about the plane-of-symmetry.

\section{B. Performance of the Inlet Types}

The second study examined the total inlet performance for the axisymmetric and two-dimensional inlets using the three-stage isentropic external supersonic diffuser. For each of the inlets, the cowl lip angles, cowl exterior factors, throat lengths and angles, and subsonic diffuser factors were all the same. Sharp cowl lips were specified for the inlets. The interior and exterior cowl lip angles were set to $10^{\circ}$ and $15^{\circ}$, respectively. The cross-sectional area through the throat was set to increase by 8 percent. The length of the subsonic diffuser was calculated to result in an equivalent conical diffusion angle of $3^{\circ}$. Table 2 summarizes the results of the designs. The two-dimensional bifurcated-duct inlet resulted in the shortest inlet, which could yield a lower-weight inlet. The two-dimensional inlets had greater frontal area on the cowl exterior, which resulted higher wave drag coefficients. All three inlets had similar values for total pressure recovery and engine flow rate.

TABLE 1.-SUMMARY OF THE EXTERNAL SUPERSONIC DIFFUSER DESIGN

\begin{tabular}{|l|c|c|c|c|c|c|c|}
\hline \multicolumn{1}{|c|}{ Inlet type } & $\theta_{\mathrm{EX}}$ & $\alpha_{\mathrm{clip}}$ & $L_{\mathrm{exd}} / D_{2}$ & $p_{t \mathrm{EX}} / p_{t L}$ & $p_{E X} / p_{L}$ & $h_{\mathrm{clip}} / D_{2}$ & $W_{2} / W_{C 2}$ \\
\hline Axi single cone & 26.72 & 12.83 & 0.4443 & 0.9728 & 2.0172 & 0.9826 & 0.7035 \\
\hline Axi double cone & 26.33 & 12.53 & 0.5964 & 0.9936 & 2.0577 & 0.9963 & 0.7232 \\
\hline Axi 3-stage isentropic & 26.62 & 13.84 & 0.6551 & 0.9992 & 2.0720 & 0.9985 & 0.7265 \\
\hline 2D single ramp & 13.76 & 13.76 & 0.6528 & 0.9667 & 2.0046 & 0.7584 & 0.7037 \\
\hline 2D double ramp & 14.33 & 14.33 & 0.9067 & 0.9906 & 2.0542 & 0.7772 & 0.7211 \\
\hline 2D triple ramp & 14.45 & 14.45 & 0.9975 & 0.9957 & 2.0648 & 0.7816 & 0.7251 \\
\hline 2D 3-stage isentropic & 14.52 & 14.52 & 1.0004 & 0.9986 & 2.0709 & 0.7839 & 0.7273 \\
\hline
\end{tabular}

TABLE 2.-SUMMARY OF THE FULL INLET DESIGN

\begin{tabular}{|l|c|c|c|c|c|c|c|}
\hline \multicolumn{1}{|c|}{ Inlet type } & $L_{\text {exd }} / D_{2}$ & $L_{\text {inlet }} / D_{2}$ & $h_{\text {clip }} / D_{2}$ & $A_{\text {cfex }} / A_{2}$ & $C_{D \text { wave }}$ & $p_{t 2} / p_{t L}$ & $W_{2} / W_{C 2}$ \\
\hline Axisymmetric & 0.656 & 2.065 & 0.9985 & 0.337 & 0.1152 & 0.9687 & 0.7265 \\
\hline 2D single-duct & 1.000 & 2.467 & 0.7839 & 0.491 & 0.1734 & 0.9680 & 0.7273 \\
\hline 2D bifurcated duct & 0.500 & 1.880 & 0.7839 & 0.714 & 0.2759 & 0.9681 & 0.7273 \\
\hline
\end{tabular}




\section{Variations in the Level of Supersonic Spillage}

The third study examined variations in the specified level of supersonic spillage for the twodimensional inlet with three ramps. Supersonic spillage can be implemented into an inlet design to allow a margin against the ingestion into the inlet of the external shock wave system or the vortices that originates from the external oblique/terminal shock interactions. Such ingestions have been shown to contribute to buzz. The specifications for the inlet geometry and conditions remain the same as those listed above. For a specified level of supersonic spillage, the design methods determined the single focal point for the oblique shock system. For zero spillage, the focal point coincides with the cowl lip. For spillage levels greater than zero, the focal point was placed above the cowl lip. All inlets operated with the same corrected engine flow rate. Table 3 summarizes the results. Since the total pressure recoveries were all the same, the actual engine flow rates were the same. With increased supersonic spillage, the length of the external supersonic diffuser and the height of the cowl lip increases. The cowl exterior factors were not changed, so increasing the height of the cowl lip resulted in a decrease in the forwardprojected area of the cowl exterior, which resulted in lower cowl wave drag. Increased supersonic spillage results in increased additive drag, but the decrease in wave drag more than compensates for the increase in additive drag.

\section{Analysis at Off-Design Mach Numbers and Angles-of-Attack}

The fourth study examined the two-dimensional single-duct inlet with three ramps analyzed for offdesign Mach numbers and angles-of-attacks. The design condition has the local Mach number $M_{L}=1.8$, local angle-of-attack $\alpha_{L}=0^{\circ}$, and zero supersonic spillage. Table 4 summarizes the performance for offdesign increments of $\Delta M_{L}= \pm 0.05$ and $\Delta \alpha_{L}= \pm 3.0^{\circ}$. The total pressure recovery seems to remain the same while the actual flow rate and drag vary significantly.

\section{E. CFD Analysis of the Axisymmetric Inlet}

The fifth study involved performing CFD analyses using the planar CFD grid for the axisymmetric, outward-turning inlet with the three-stage, isentropic external supersonic diffuser. The inflow was at Mach 1.8 and zero degrees angle-of-attack. A supersonic spillage ratio of 2 percent was specified. The inlet had a blunt cowl lip with a circular profile of radius $0.002 \mathrm{ft}$. The throat area increased 6 percent over its length of $1.0 \mathrm{ft}$. The subsonic diffuser was specified to be $4.0 \mathrm{ft}$ in length. All other factors were the same as specified. Figure 15 shows the flow domain for the simulations.

TABLE 3.-SUMMARY OF THE DESIGN OF A TRIPLE-RAMP, TWO-DIMENSIONAL SINGLE-DUCT INLET WITH VARIOUS LEVELS OF SUPERSONIC SPILLAGE

\begin{tabular}{|c|c|c|c|c|c|c|c|c|c|}
\hline$W_{\text {spillage }} / W_{\text {cap }}$ & $W_{2} / W_{\text {cap }}$ & $p_{t 2} / p_{t L}$ & $L_{\text {exd }} / D_{2}$ & $L_{\text {inlet }} / D_{2}$ & $h_{\text {clip }} / D_{2}$ & $A_{\text {cfex }} / A_{2}$ & $C_{D \text { wave }}$ & $C_{\text {Dadd }}$ & $C_{D \text { inlet }}$ \\
\hline 0.00 & 1.00 & 0.9652 & 0.9975 & 2.4638 & 0.7816 & 0.4941 & 0.1755 & 0.0000 & 0.1755 \\
\hline 0.01 & 0.99 & 0.9652 & 1.0410 & 2.5074 & 0.7895 & 0.4836 & 0.1663 & 0.0038 & 0.1701 \\
\hline 0.02 & 0.98 & 0.9652 & 1.0855 & 2.5518 & 0.7975 & 0.4729 & 0.1594 & 0.0075 & 0.1669 \\
\hline 0.04 & 0.96 & 0.9652 & 1.1771 & 2.6434 & 0.8141 & 0.4509 & 0.1455 & 0.0150 & 0.1605 \\
\hline
\end{tabular}

TABLE 4.-SUMMARY OF THE ANALYSIS OF A TRIPLE-RAMP, TWO-DIMENSIONAL SINGLE-DUCT INLET AT OFF-DESIGN MACH NUMBERS AND ANGLES-OF-ATTACK

\begin{tabular}{|c|c|c|c|c|c|c|}
\hline$M_{L}$ & $\alpha_{L}$ & $W_{2} / W_{C 2}$ & $p_{t 2} / p_{t L}$ & $C_{D \text { wave }}$ & $C_{D \text { add }}$ & $C_{D \text { inlet }}$ \\
\hline 1.80 & 0.00 & 0.7251 & 0.9652 & 0.1755 & 0.0000 & 0.1755 \\
\hline 1.75 & 0.00 & 0.6793 & 0.9652 & 0.1823 & 0.0079 & 0.1902 \\
\hline 1.85 & 0.00 & 0.7744 & 0.9651 & 0.1675 & 0.0000 & 0.1675 \\
\hline 1.80 & 3.00 & 0.7251 & 0.9659 & 0.1339 & -0.0103 & 0.1236 \\
\hline 1.80 & -3.00 & 0.7251 & 0.9625 & 0.2221 & 0.0202 & 0.2424 \\
\hline
\end{tabular}




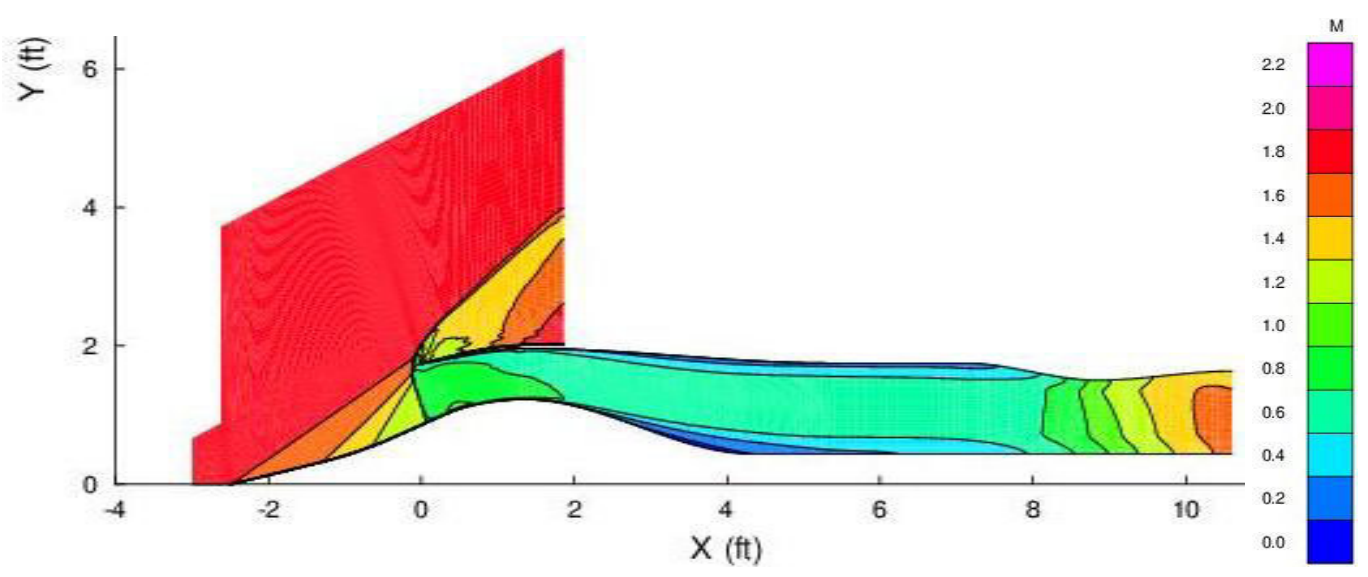

Figure 15.-Flow domain and Mach number contours for the CFD simulation of the axisymmetric, outward-turning inlet at sub-critical operation.

TABLE 5.-INLET PERFORMANCE FROM THE CFD ANALYSES AT VARIOUS LEVELS OF INLET BACK-PRESSURE

\begin{tabular}{|c|c|c|c|c|c|}
\hline$A_{\text {noz }} / A_{2}$ & $W_{2} / W_{\text {cap }}$ & $M_{2}$ & $p_{t 2} / p_{t 0}$ & $p_{2} / p_{0}$ & $C_{D \text { wave }}$ \\
\hline 0.720 & 0.9364 & 0.4825 & 0.9540 & 4.6457 & 0.1195 \\
\hline 0.730 & 0.9540 & 0.4892 & 0.9605 & 4.6640 & 0.1285 \\
\hline 0.735 & 0.9616 & 0.4926 & 0.9625 & 4.6670 & 0.1318 \\
\hline 0.740 & 0.9704 & 0.4968 & 0.9654 & 4.6683 & 0.1368 \\
\hline 0.745 & 0.9747 & 0.5113 & 0.9589 & 4.5564 & 0.1386 \\
\hline 0.750 & 0.9750 & 0.5190 & 0.9518 & 4.4890 & 0.1389 \\
\hline 0.760 & 0.9751 & 0.5239 & 0.9417 & 4.4431 & 0.1389 \\
\hline
\end{tabular}

The inflow and farfield boundaries were placed away from the inlet such that freestream boundary conditions could be imposed. The engine face station 2 was located at $\mathrm{x}=5.35 \mathrm{ft}$. The nozzle block attached downstream of the engine-face shows a constant-area section followed by a convergingdiverging nozzle. The nozzle throat was sized to create a back-pressure for the critical operating point for the inlet. At the exit of the nozzle, a supersonic outflow boundary condition was imposed. The surfaces of the inlet were modeled as adiabatic, no-slip walls. The planar grid consisted of 27 structured-grid blocks with a total of 98361 grid points. The grid spacing values at the cowl lip, throat, and engine face were $0.0001,0.01$, and $0.0625 \mathrm{ft}$, respectively. This resulted in 427 grid points distributed axially between the cowl lip and engine face. The grid spacing normal to the wall was $0.0001 \mathrm{ft}$, which corresponded to a $y^{+}$ for the first point off the wall of approximately $y^{+}=5$. From the centerbody to the cowl, there were 135 grid points. Figure 15 shows the Mach number contours and indicates the shock and Mach waves of the supersonic flow and the variations of the subsonic flow downstream of the terminal shock.

The CFD simulations were performed over a range of outflow nozzle throat areas to vary the inlet flow from sub-critial to super-critical. Table 5 lists the various inlet performance measures over a range of inlet back-pressures as set by the outflow nozzle. As the nozzle is opened, the engine flow ratio $\left(W_{2} /\right.$ $W_{\text {cap }}$ ) increases to its maximum, choked value as the inlet becomes super-critical. The mass-averaged Mach number at the engine face $\left(M_{2}\right)$ varies about the design value of $M_{2}=0.5$. The total pressure recovery $\left(p_{t 2} / p_{t 0}\right)$ increases and then drops. Figure 16 shows the characteristic "cane" curve of the variation of the total pressure recovery with engine flow ratio. Also plotted is the total pressure recovery for the critical operating point as computed by SUPIN. It is evident from Table 5 and Figure 16 that the CFD analysis indicates approximately 2.5 percent supersonic spillage rather than the 2.0 percent specified within SUPIN. The static pressure ratio similarly rises and then drops. The wave drag coefficient increases and then remains fixed for the super-critical flow rates. Figure 17 shows Mach number contours of the shocks and flow about the inlet entrance for the sub-critical, critical, and super-critical operating points. 


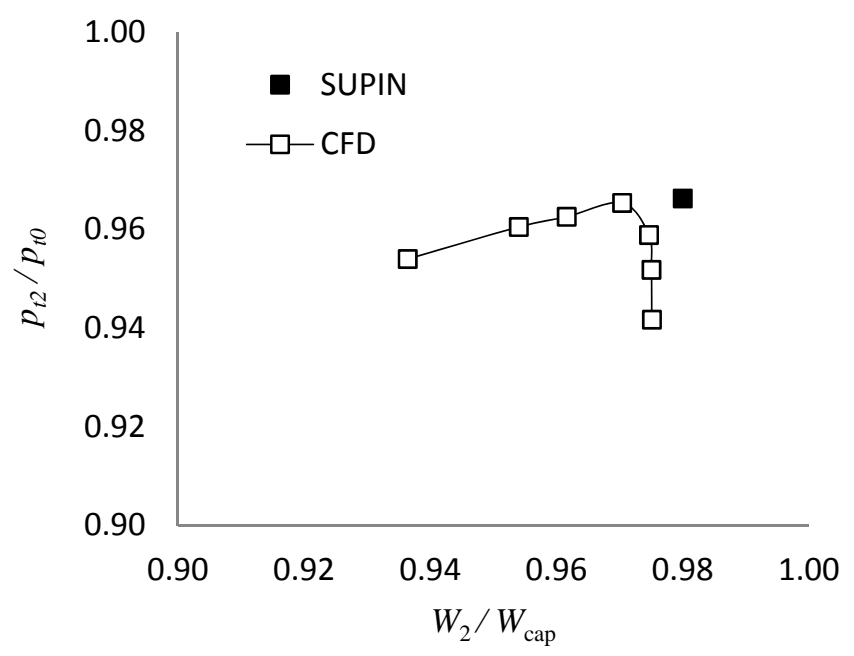

Figure 16.-Characteristic "cane" curve from the CFD simulations of the axisymmetric, outward-turning inlet.

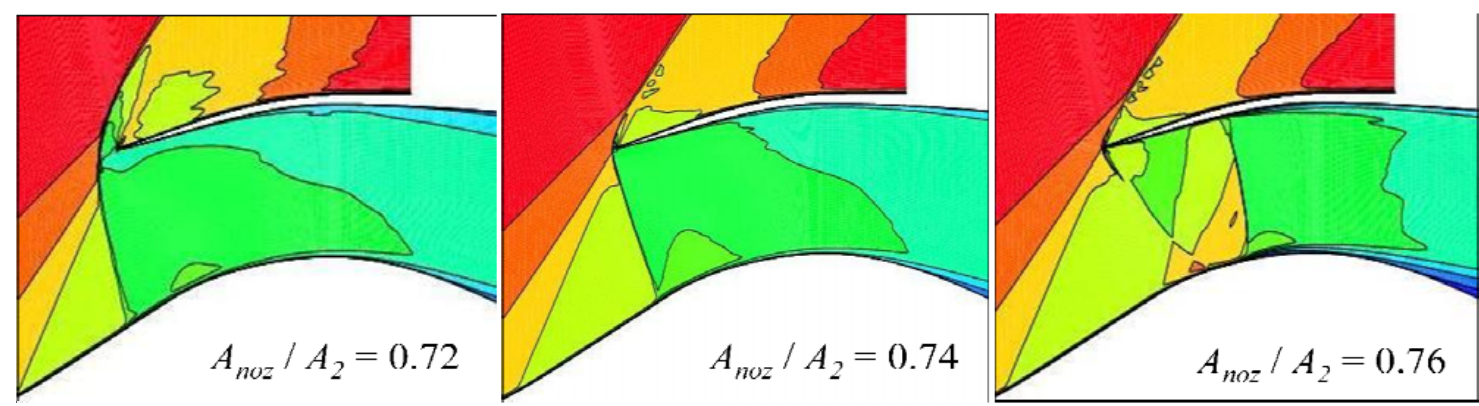

Figure 17.-Mach contours at sub-critical (left), critical (center), and super-critical (right) operation of the axisymmetric, outward-turning inlet.

TABLE 6.-COMPARISON OF CFD AND SUPIN RESULTS AT THE CRITICAL OPERATING POINT

\begin{tabular}{|c|c|c|c|c|c|}
\hline Method & $W_{2} / W_{\text {cap }}$ & $M_{2}$ & $p_{t 2} / p_{t 0}$ & $p_{2} / p_{0}$ & $C_{D \text { wave }}$ \\
\hline SUPIN & 0.9800 & 0.5000 & 0.9663 & 4.6802 & 0.1371 \\
\hline CFD & 0.9704 & 0.4968 & 0.9654 & 4.6683 & 0.1368 \\
\hline$\% \Delta$ & $-0.98 \%$ & $-0.63 \%$ & $-0.09 \%$ & $-0.25 \%$ & $-0.21 \%$ \\
\hline
\end{tabular}

Table 6 compares the various inlet performance measures at the critical operating point as computed from SUPIN and from the CFD analysis. The CFD results are those listed in Table 2 for $A_{\text {noz }} / A_{2}=0.740$, which is assumed to approximate the critical operating point of the inlet. The CFD simulation indicates slightly greater supersonic spillage. This increased spillage is due to the blockage of the boundary layer on the centerbody. An inviscid CFD analysis of the inlet was performed and yielded a supercritical flow rate of $W_{2} / W_{\text {cap }}=0.9789$, which is 0.11 percent below the supersonic spillage specified within SUPIN. A modification to SUPIN could be the estimation of the boundary layer displacement thickness on the external supersonic diffuser and the subsequent adjustment of the capture area to account for the boundary layer blockage. The mass-averaged Mach number of the CFD simulation is slightly different from the value specified within SUPIN $\left(M_{2}=0.5\right)$; however, this is most likely due to the use of the outflow nozzle to approximate the critical operating point. A CFD simulation could be performed for which the engine-face Mach number is specified as the boundary condition at station 2 . However, the results of Table 6 were sufficient for the purpose of this paper. The total pressure recovery, static pressure ratio, and wave drag coefficient of the CFD simulation agreed well with the values indicated by SUPIN. Overall, this provides some confidence in the aerodynamic models within SUPIN for designing and analyzing axisymmetric, outward-turning inlets. 
Similar planar CFD analyses could be conducted for the two-dimensional inlets. However, the sidewalls of the two-dimensional inlets make the flow three-dimensional, and so, planar analyses would only provide a general sense of the flow through two-dimensional inlets. Likewise, the streamline-traced inlet is a three-dimensional flowfield. Thus, for these inlets, one should start with the surface grids and using a grid generation software system, create a three-dimensional CFD grid and perform a threedimensional flow analysis.

\section{Summary}

The geometry and aerodynamic modeling of external-compression supersonic inlets is available within the SUPIN Fortran code. SUPIN models the geometry of a set of inlets using simple planar geometry constructs. The aerodynamic performance of the inlet is computed using low-fidelity and quick analytic, empirical, and numerical methods. The aerodynamic performance includes the flow rates, total pressure recovery, and drag. SUPIN provides surface grids suitable for higher-fidelity analysis using methods of computational fluid dynamics. Further development of SUPIN will provide greater capabilities for off-design analysis and modeling internal supersonic compression for the design and analysis of mixed-compression supersonic inlets.

\section{References}

1. Welge, H.R., Nelson, C., and Bonet, J., "Supersonic Vehicle Systems for the 2020 to 2035 Timeframe,” AIAA-2010-4930, June 2010.

2. Morgenstern, J.M., Norstrud, N., Stelmack, M., and Jha, P.D., "Advanced Concept Studies for Supersonic Commercial Transports Entering Service in 2030-2035 (N+3),” AIAA-2010-5114, June 2010.

3. Conners, T.R. and Wayman, T.R., "The Feasibility of High-Flow Nacelle Bypass for Low Sonic Boom Propulsion System Design,” AIAA-2011-3797, June 2011.

4. Seddon, J. and E.L. Goldsmith, Intake Aerodynamics, AIAA Education Series, New York, 1985.

5. Seddon, J. and E.L. Goldsmith, editors, Practical Intake Aerodynamic Design, AIAA Education Series, New York, 1993.

6. Mahoney, J.J., Inlets for Supersonic Missiles, AIAA Education Series, Washington, DC, 1990.

7. Ferri, A. and Nucci, L.M., "Preliminary Investigation of a New Type of Supersonic Inlet," NACA RM L6J31, November 1946.

8. Taylor, G.I. and Maccoll, J.W., “The Air Pressure on a Cone Moving at High Speeds,” Proceedings of the Royal Society (London), Series A, vol. 139, no. 839, February 1, 1933, pp. 278-311.

9. Oswatitsch, K., "Pressure Recovery for Missiles with Reaction Propulsion at High Supersonic Speeds (The Efficiency of Shock Diffusers),” NACA TM 1140, June 1947 (English translation of Report 1005 of the Research and Development Department of the Army Weapons Office, Göttingen, Germany, 1944).

10. Porcher, C.E. and Thebiay, F.J., "Development of the Variable Geometry Inlet for the B-58 Airplane,” SAE 595N, October 1962.

11. Johnson, C.L., "Some Development Aspects of the YF-12A Interceptor Aircraft," AIAA Journal of Aircraft, vol. 7, no. 4, p. 355-359, 1970.

12. Hirt, S.M., Chima, R.V., Vyas, M.A., Conners, T.R., Wayman, T.R., and Reger, R.W., "Experimental Investigation of a Large-Scale Low-Boom Inlet Concept,” AIAA-2011-3796, June 2011.

13. Ames Research Staff, "Equations, Tables, and Charts for Compressible Flow,” NACA Report 1135, 1953.

14. Anderson, J.D., Jr., Modern Compressible Flow, McGraw-Hill Book Company, New York, 1982.

15. Imfeld, W.F., "Development Program for the F-15 Inlet," AIAA Journal of Aircraft, vol. 13, no. 4, p. 286-291, April 1976. 
16. Rettie, I.H. and Lewis, W.G.E., "The Design and Development of an Air Intake for a Supersonic Transport Aircraft,” AIAA-1967-0752, October 1967.

17. Candel, S., "Concorde and the Future of Supersonic Transport," AIAA Journal of Propulsion and Power, Vol. 20, No. 1, January-February 2004, p. 59-68.

18. Wasserbauer, J.F., Meleason, E.T., and Burstadt, P.L., "Experimental Investigation of the Performance of a Mach 2.7 Two-Dimensional Bifurcated Inlet With 30 Percent Internal Contraction,” NASA TM-106728, May 1996.

19. Mölder, S. and Szpiro, E.J., "Busemann Inlet for Hypersonic Speeds,” AIAA Journal of Spacecraft and Rockets, vol. 3, no. 8, pp. 1303-1304, August 1966.

20. Van Wie, D. and S. Mölder, "Applications of Busemann Inlet Designs for Flight at Hypersonic Speeds,” AIAA-1992-1210, February 1992.

21. Billig, F.S., Baurle, R.A., Tam, C.-J., and Wornom, S.F., "Design and Analysis of Streamline Traced Hypersonic Inlets,” AIAA-1999-4974, November 1999.

22. Koncsek, J.L., "Supersonic External-Compression Diffuser and Method for Designing Same,” Patent 6793175, September 2004.

23. Slater, J.W., Davis, D.O., Sanders, B.W., and Weir, L.J., "Role of CFD in the Aerodynamic Design and Analysis of the Parametric Inlet,” ISABE-2005-1168, 2005.

24. Vinogradov, V.A. and Stepanov, V.A., "Scheme and Inlet Performance of Supersonic Business Aircraft,” AIAA-2008-4585, July 2008.

25. Moeckel, W.E., "Approximate Methods for Predicting Form and Location of Detached Shock Waves Ahead of Plane or Axially Symmetric Bodies,” NACA TN 1921, 1949.

26. Henry, J.R., Wood, C.C., and Wilbur, S.W., "Summary of Subsonic-Diffuser Data,” NACA RM L56F05, 1956.

27. Tindell, R. and Tamplin, G., “An Inlet System Installed Performance Prediction Program using Simplified Modeling,” AIAA-1983-1167, June 1983.

28. Haas, M., Elmquist, R.A., Sobel, D.R., "The NIDA Code: A New Tool for Supersonic Inlet Design and Analysis,” JANNAF Propulsion Meeting, November 1993.

29. Barnhart, P.J., "IPAC - Inlet Performance Analysis Code,” NASA CR-204130, July 1997.

30. Sorensen, V.L., "Computer Program for Calculating Flow Fields in Supersonic Inlets,” NASA TN D-2897, July 1965.

31. Anderson, B.H., "Design of Supersonic Inlets by a Computer Program Incorporating the Method of Characteristics," NASA TN D-4960, January 1969.

32. Varner, M.O., Martindale, W.R., Phares, W.J., Kneile, K.R., and Adams Jr., J.C., “Large Perturbation Flow Field Analysis and Simulation for Supersonic Inlets - Final Report," NASA CR 174576, September 1984.

33. Geiselhart, K.A., Ozoroski, L.P., Fenbert, J.W., Shields, E.W., and Li, W., "Integration of Multifidelity Multidisciplinary Computer Codes for Design and Analysis of Supersonic Aircraft," AIAA-2011-0465, January 2011.

34. SAE, Aerospace Standard (AS) 755, “Aircraft Propulsion System Performance Station Designation and Nomenclature,” December 1997.

35. Koncsek, J.L., “An Approach to Conformal Inlet Diffuser Design for Integrated Propulsion Systems,” AIAA-1981-1395, July 1981.

36. Fradenburgh, E.A. and Wyatt, D.D., "Theoretical Performance Characteristics of Sharp-Lip Inlets at Subsonic Speeds,” NACA Report 1193, 1954.

37. Blackaby, J.R. and Watson, E.C., "An Experimental Investigation at Low Speeds of the Effects of Lip Shape on the Drag and Pressure Recovery of a Nose Inlet in a Body of Revolution,” NACA TN 3170, 1954.

38. Barnhart, P.J., “A Non-Axisymmetric Linearized Supersonic Wave Drag Analysis: Mathematical Theory,” NASA CR 198430, May 1996.

39. Walatka, P.P., Buning, P.G., Pierce, L., and Elson, P.A., "PLOT3D User’s Manual,” NASA-TM-101067, March 1990. 


\begin{tabular}{|c|c|c|}
\hline \multicolumn{2}{|c|}{ REPORT DOCUMENTATION PAGE } & $\begin{array}{l}\text { Form Approved } \\
\text { OMB No. 0704-0188 }\end{array}$ \\
\hline \multicolumn{3}{|c|}{ 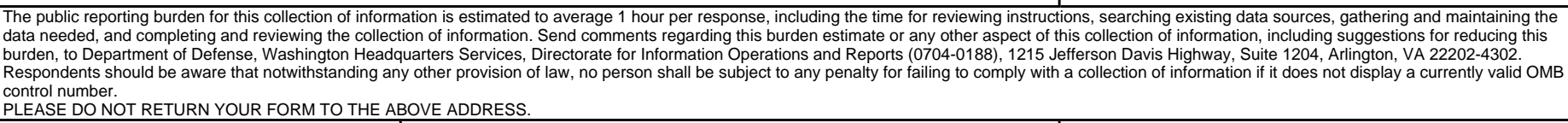 } \\
\hline $\begin{array}{l}\text { 1. REPORT DATE (DD-MM-YYYY) } \\
01-08-2012\end{array}$ & $\begin{array}{l}\text { 2. REPORT TYPE } \\
\text { Technical Memorandum }\end{array}$ & 3. DATES COVERED (From - To) \\
\hline \multirow{3}{*}{\multicolumn{2}{|c|}{$\begin{array}{l}\text { 4. TITLE AND SUBTITLE } \\
\text { Design and Analysis Tool for External-Compression Supersonic Inlets }\end{array}$}} & 5a. CONTRACT NUMBER \\
\hline & & 5b. GRANT NUMBER \\
\hline & & 5c. PROGRAM ELEMENT NUMBER \\
\hline \multirow{3}{*}{\multicolumn{2}{|c|}{$\begin{array}{l}\text { 6. AUTHOR(S) } \\
\text { Slater, John, W. }\end{array}$}} & 5d. PROJECT NUMBER \\
\hline & & 5e. TASK NUMBER \\
\hline & & $\begin{array}{l}\text { 5f. WORK UNIT NUMBER } \\
\text { WBS 984754.02.07.03.13.02 }\end{array}$ \\
\hline \multicolumn{2}{|c|}{$\begin{array}{l}\text { 7. PERFORMING ORGANIZATION NAME(S) AND ADDRESS(ES) } \\
\text { National Aeronautics and Space Administration } \\
\text { John H. Glenn Research Center at Lewis Field } \\
\text { Cleveland, Ohio 44135-3191 }\end{array}$} & $\begin{array}{l}\text { 8. PERFORMING ORGANIZATION } \\
\text { REPORT NUMBER } \\
\text { E-18337 }\end{array}$ \\
\hline \multirow{2}{*}{\multicolumn{2}{|c|}{$\begin{array}{l}\text { 9. SPONSORING/MONITORING AGENCY NAME(S) AND ADDRESS(ES) } \\
\text { National Aeronautics and Space Administration } \\
\text { Washington, DC 20546-0001 }\end{array}$}} & $\begin{array}{l}\text { 10. SPONSORING/MONITOR'S } \\
\text { ACRONYM(S) } \\
\text { NASA }\end{array}$ \\
\hline & & $\begin{array}{l}\text { 11. SPONSORING/MONITORING } \\
\text { REPORT NUMBER } \\
\text { NASA/TM-2012-217660 }\end{array}$ \\
\hline \multicolumn{3}{|c|}{$\begin{array}{l}\text { 12. DISTRIBUTIONIAVAILABILITY STATEMENT } \\
\text { Unclassified-Unlimited } \\
\text { Subject Category: } 07 \\
\text { Available electronically at http://www.sti.nasa.gov } \\
\text { This publication is available from the NASA Center for AeroSpace Information, 443-757-5802 }\end{array}$} \\
\hline
\end{tabular}

\section{SUPPLEMENTARY NOTES}

\section{ABSTRACT}

A computational tool named SUPIN has been developed to design and analyze external-compression supersonic inlets for aircraft at cruise speeds from Mach 1.6 to 2.0. The inlet types available include the axisymmetric outward-turning, two-dimensional single-duct, twodimensional bifurcated-duct, and streamline-traced Busemann inlets. The aerodynamic performance is characterized by the flow rates, total pressure recovery, and drag. The inlet flowfield is divided into parts to provide a framework for the geometry and aerodynamic modeling and the parts are defined in terms of geometric factors. The low-fidelity aerodynamic analysis and design methods are based on analytic, empirical, and numerical methods which provide for quick analysis. SUPIN provides inlet geometry in the form of coordinates and surface grids useable by grid generation methods for higher-fidelity computational fluid dynamics (CFD) analysis. SUPIN is demonstrated through a series of design studies and CFD analyses were performed to verify some of the analysis results.

\section{SUBJECT TERMS}

Supersonic inlets

\begin{tabular}{|c|c|c|c|c|}
\hline \multicolumn{3}{|c|}{ 16. SECURITY CLASSIFICATION OF: } & \multirow{2}{*}{$\begin{array}{l}\text { 17. LIMITATION OF } \\
\text { ABSTRACT } \\
\text { UU }\end{array}$} & \multirow{2}{*}{$\begin{array}{l}\text { 18. NUMBER } \\
\text { OF } \\
\text { PAGES } \\
29\end{array}$} \\
\hline $\begin{array}{l}\text { a. REPORT } \\
U\end{array}$ & $\begin{array}{l}\text { b. ABSTRACT } \\
\mathrm{U}\end{array}$ & $\begin{array}{l}\text { c. THIS } \\
\text { PAGE } \\
\text { U }\end{array}$ & & \\
\hline
\end{tabular}


